\title{
STS-133/ET-137 Tanking Test Photogrammetry Assessment
}

Stanley T. Oliver ${ }^{1}$

NASA Marshall Space Flight Center, Huntsville, AL

Extended Abstract of Proposed Paper for the 53 ${ }^{\text {rd }}$ AIAA/ASME/ASCE/AHS/ASC Structures, Structural Dynamics, and Materials Conference, April 23-26, 2012, Honolulu, Hawaii

Category: Structures

INTRODUCTION

Following the launch scrub of Space Shuttle mission STS-133 on November 5, 2010, an anomalous condition of cracked and raised thermal protection system (TPS) foam was observed on the External Tank (ET). Subsequent dissection of the affected TPS region revealed cracks in the feet of two Intertank (IT) metallic stringers. An extensive investigation into the cause(s) and corrective action(s) for the cracked stringers was initiated, involving a wide array of material and structural tests and nondestructive evaluations, with the intent to culminate into the development of flight rational. One such structural test was the instrumented tanking test performed on December 17, 2010. The tanking test incorporated two three-dimensional optical displacement measurement systems to measure full-field outer surface displacements of the TPS surrounding the affected region that contained the stringer cracks. The results showed that the radial displacement and rotation of the liquid oxygen (LO2) tank flange changed significantly as the fluid level of the LO2 approached and passed the LO2 tank flange.

\section{BACKGROUND-EXTERNAL TANK DESIGN}

The Space Shuttle flight vehicle is shown in Figure 1, consisting of the Orbiter, two Solid Rocket Boosters (SRBs), and the ET. The three primary structural components of the ET are two propellant tanks (a liquid hydrogen (LH2) tank and a LO2 tank) and the IT, shown expanded in Figure 2. The IT is a stiffened cylindrical structure consisting of eight mechanically joined panels (two integrally-machined stiffened thrust panels to react booster loads and six hatstiffened skin panels) shown in Figure 3. Figure 4 shows the basic construction of a typical hatstiffened skin (skin-stringer) panel.

\section{BACKGROUND-TANKING TEST}

The dissection of the affected TPS region revealed cracks in the feet of two IT metallic stringers (S6-2 \& S7-2). The cracked length of the two affected stringers were replaced with a standard repair, which included a new stringer portion, splice joint, and the addition of radius blocks on the feet of the stringers. Video evidence of the launch scrub narrowed the time of occurrence of the cracked stringers to when the liquid oxygen in the LO2 tank was near the LO2 flange.

\footnotetext{
${ }^{1}$ Aerospace Engineer.
} 
Therefore, to expose the repaired stringers to this same thermal environment, a tanking test was performed. The tanking test sequence followed the standard launch procedures and time-line.

The region of the repair was instrumented with strain gages and thermocouples, to (1) ascertain the presence of any unforeseen structural design issues of the repair and (2) assist in grounding analysis models [1]. In addition, a similar instrumentation package was applied to panel 3, an unrepaired site of similar structural geometry, to facilitate collection of direct comparative data between repaired and as-built response to thermal environments.

A comparative assessment between repaired and as-built regions was also planned using threedimensional optical displacement measurement systems. The radial displacement of the IT and LO2 tank as the LO2 approached and passed the LO2 flange was of particular interest; therefore, photogrammatic speckle patterns were applied to the outer surface of the TPS near the LO2 flange. The photogrammatic speckle patterns were applied to panel 2 (the repaired site) and panel 6 (representing the as-built region).

The photogrammetry camera systems (ARAMIS 3D Image Correlation Systems) were mounted to the Launch Complex 39A Fixed Support Structure (FSS). The camera system used to image the repaired region of panel 2 was sixty feet away. The camera system used to image the as-built region of panel 6 was only thirty feet away. An over-head sketch of the ET, two SRBs, and the FSS is shown in Figure 5. The eight IT panels, the location of the two photogrammetry camera systems and their distance from the ET, and the instrumentation and photogrammatic speckle pattern locations are also shown.

The photogrammetry system used to image the repaired region of panel 2 lost its calibration and did not yield reliable deformation results. The photogrammetry system used to image the asbuilt region of panel 6 remained in calibration throughout the duration of the test and provided useful displacement data. The comparative assessment between the two panels could not be performed; however, the displacement results from panel 6 provided valuable data to assess. The analyses, results and conclusions presented herein pertain only to panel 6.

The dimensions of the T-shaped photogrammatic speckle pattern applied to panel 6 are shown in Figure 6. The underlying structure of panel 6 relative to the speckle pattern is shown in Figure 7. The eighteen stringers are shown as well as the single and double skin doubler regions. Also shown is the location of the internal I-beam. Lastly, sixteen lines equally spaced across the width of the speckle pattern are shown. These lines are located on the stringer tops and stringer valleys, and represent the locations where radial displacement data was analyzed. 


\section{ANALYSIS}

The photogrammetry system captured images throughout the entire test, from just prior to the beginning of LO2 fill until the LO2 tank had nearly been drained. The time span from first image to last is greater than nine hours. A total of 1637 images were captured, with the following frequencies:

Every 10 seconds during fill (for approximately 175 minutes)

Every 60 seconds during stable replenish (for approximately 240 minutes)

Every 6 seconds during pre-pressurization (for approximately 12 minutes)

Every 10 seconds during drain (for approximately 28 minutes

Every 60 seconds during remainder of drain (for approximately 105 minutes).

The assessment investigated the radial displacement data from the photogrammetry system. The displacement data was studied along the stringer tops and valleys along sixteen vertical lines that extend from top to bottom of the speckle region, with emphasis on the radial contraction and rotation of the LO2 flange.

The LO2 flange was obscured by the TPS, which made it difficult to locate the position of the flange beneath the speckled region. However, design drawings of the LO2 flange closeout TPS application indicate that the mating surface between the LO2 and IT flange is 6.30 inches above the intersection of the IT and LO2 flange close-out TPS application [2]. This intersection is clearly visible in Figure 8(a), a photograph of the flange closeout. The lighter colored TPS in the center of the photograph is the LO2 flange TPS close-out application, while the darker colored TPS covers the LO2 tank and IT. Figure 8(b) shows a cross sectional schematic of the LO2 flange region, showing the LO2 and IT metallic components and the TPS coverage.

The LO2 flange rotation computation methodology used inverse trigonometric relationships, relating the out-of-plane displacements (w) and y-coordinates (y) to the rotation. Figure 9(a) shows the methodology for calculating the rotation at the data point closest to the LO2 flange. Figure 9(b) is a cross section schematic depicting the LO2 flange region and the approximate range of the photogrammetry data used in the calculation of the rotation.

Although the data collection during the tanking test was from beginning of the fill until the LO2 tank was nearly empty, the primary times of interest were during the initial phases of the tanking, when the LO2 fluid level approaches and passes the LO2 flanges until steady-state. The first 1200 images were studied, which incorporated the fill and replenish time frames. The data studied represented approximately the first seven hours $(24,000$ seconds) of the test.

\section{RESULTS}

The computed values from the test data for the LO2 flange rotation are shown in Figure 10, showing the flange rotation as a function of time. As the LO2 filled the LO2 dome, the flange began to rotate due to the thermal gradients within the LO2 tank and IT. As the LO2 fluid level approached and passed the LO2 flange, a sharp increase in flange rotation was observed. As the thermal gradients continued to reach steady-state, the rotation angle relaxed to its steady-state position. In Figure 10, the flange rotations for fourteen of the sixteen lines are shown versus 
time. Two lines were omitted due to missing data in the area of interest. The average of the fourteen lines is shown in Figure 11. Also shown in Figure 11 are circular markers that represent finite element results using a single stringer finite element model, which utilized the temperature data from the tanking test.

The radial displacement of the $\mathrm{LO} 2$ flange was also of interest. The LO2 displacement computation read the displacement data directly from the results file. However, this displacement includes the rigid body motion. All displacements were grounded to the radial motion of the IT internal frame. The resulting $\mathrm{LO} 2$ flange displacement as a function of time is shown in Figure 12. Similar to the LO2 flange rotation assessment, the radial displacement began small and then suddenly increased as the $\mathrm{LO} 2$ fluid level approached the $\mathrm{LO} 2$ flange. However, unlike the rotation, the displacements did not relax, but maintained their value through steady-state. The average displacement data is shown in Figure 13 which also contains circular markers representing the finite element displacement results.

\section{CONCLUSIONS}

The photogrammetry analysis of STS-133/ET-137 determined that the displacements and rotation of the $\mathrm{LO} 2$ flange was strongly influenced by the fluid level of the liquid oxygen and the thermal gradients within both the LO2 tank and IT. As the fluid level approached the LO2 flange, the flange rotation and radial contraction was observed to change quickly. However, as the IT temperature profile approached steady-state, the flange rotation relaxed while the radial displacements maintained their position. These results confirmed the finite element predictions that the worst-case flange rotation was during the thermal transient phase of the tank filling process.

\section{REFERENCES}

1. Smith, R. (2011). STS-133/ET-137 Instrumented Tank Test Assessment of Strain-Gage Data, Lockheed Martin Report TBD.

2. Lockheed Martin Corporation, (2002). Foam Closeout-LO2 Tank Intertank STA 852.0, P/L BRKT STS 861.98, Aero Vents, 80971118414-510, Sheet 31, Section A-A.

\section{ACKNOWLEDGEMENTS}

The author would like to acknowledge Mr. Tim Schmidt of Trilion Quality Systems for his dedication and support provided to the STS-133 tanking test. Mr. Schmidt's expertise was crucial in the set-up and operation of the ARAMIS photogrammery systems as well as the postprocessing of the data.

The author would also like to acknowledge Mr. Brian Steeve of Marshall Space Flight Center for the finite element result data to illustrate the correlation between the photogrammetry and analysis results. 


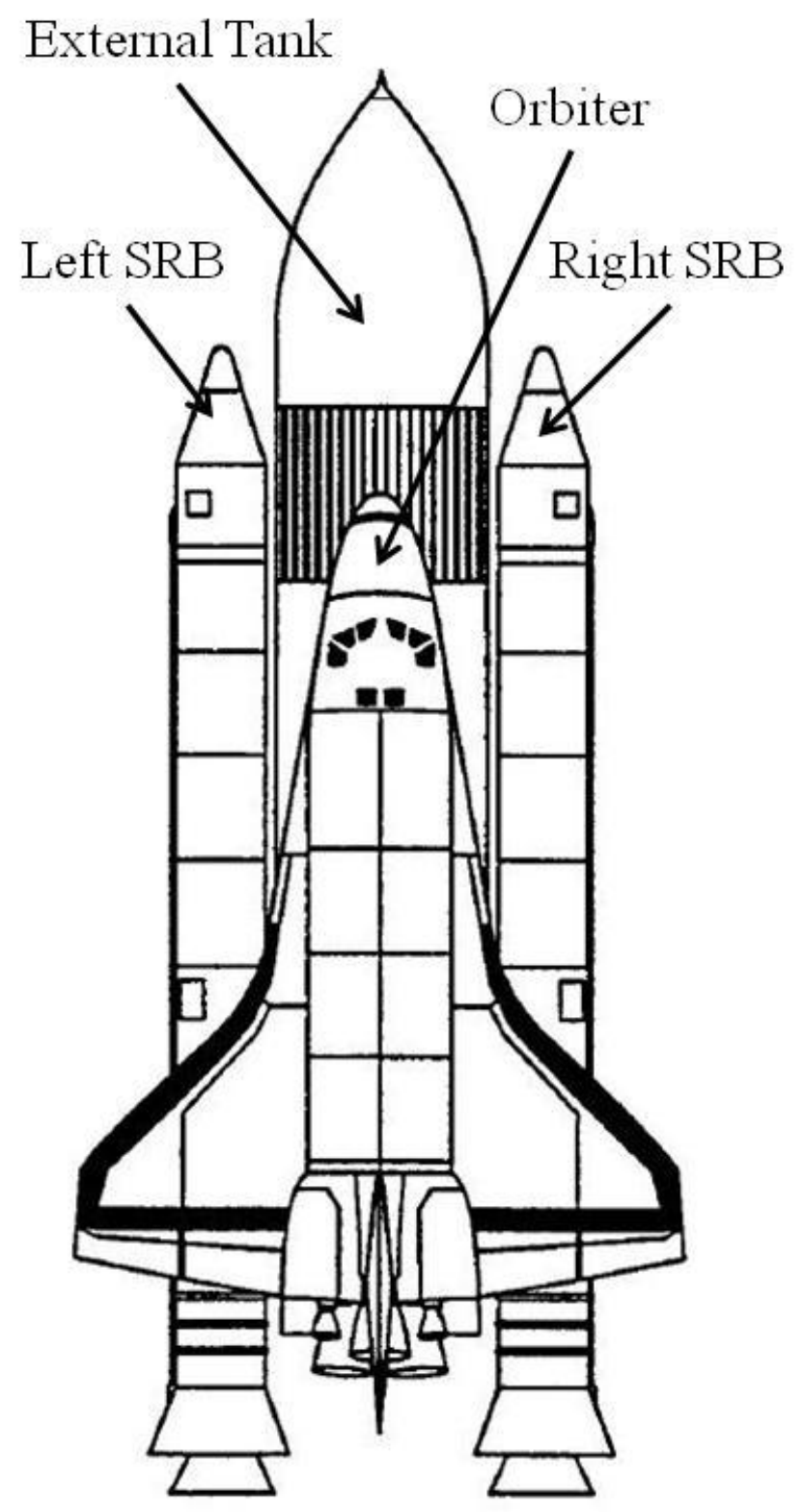

Figure 1. The Space Shuttle flight vehicle. 


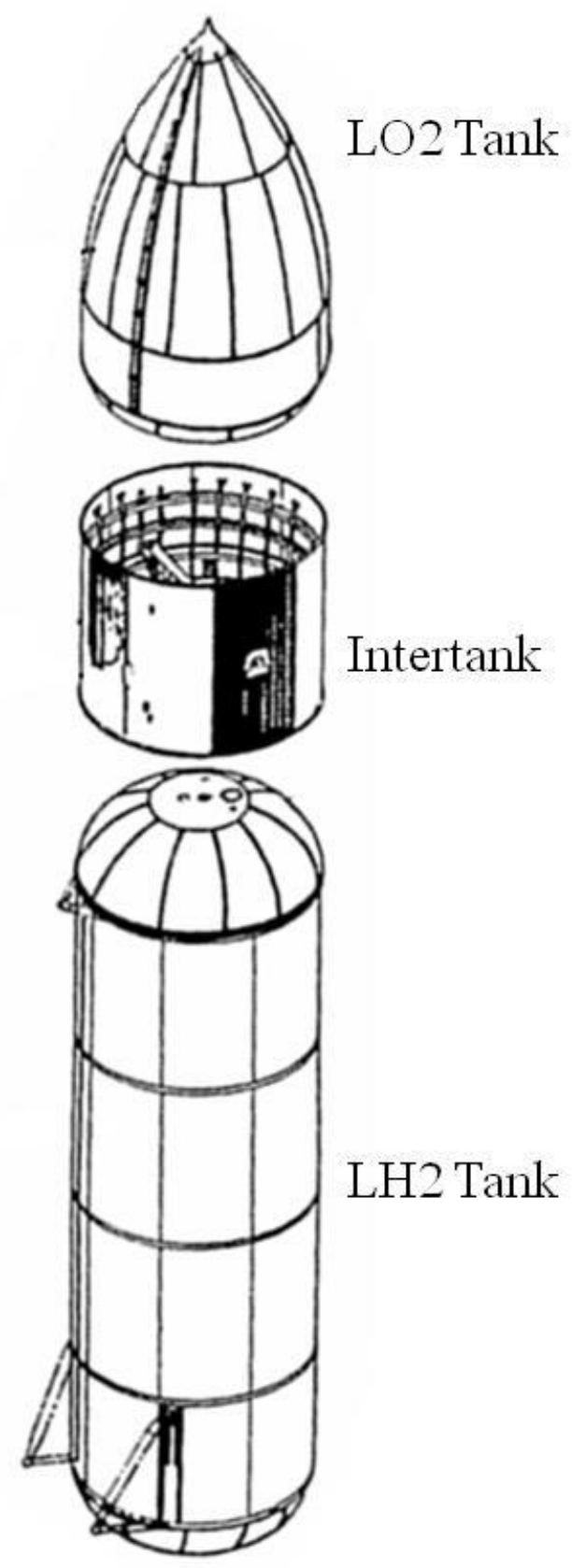

Figure 2. Expanded view of the External Tank's primary structural components. 


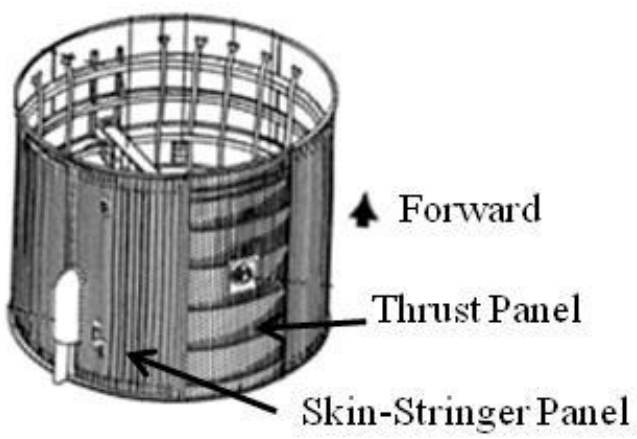

Figure 3. General view of Interank.
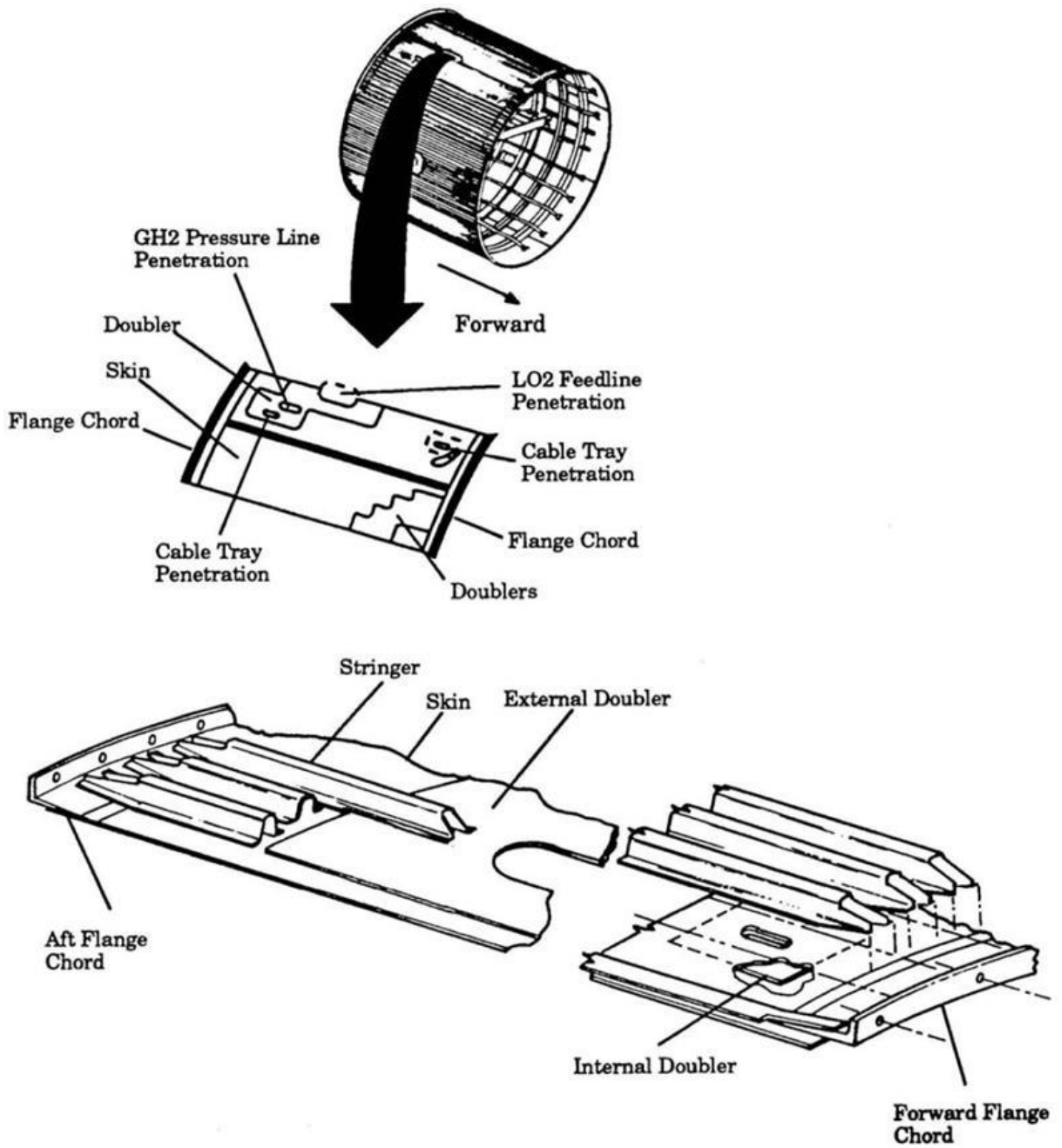

Figure 4. Basic construction of Intertank skin-stringer panel. 
Strain gage and

Thermocouple Locations

O

Photogrammetry Speckle

Pattern Locations

$\triangle$ Photogrammetry Camera

System Locations

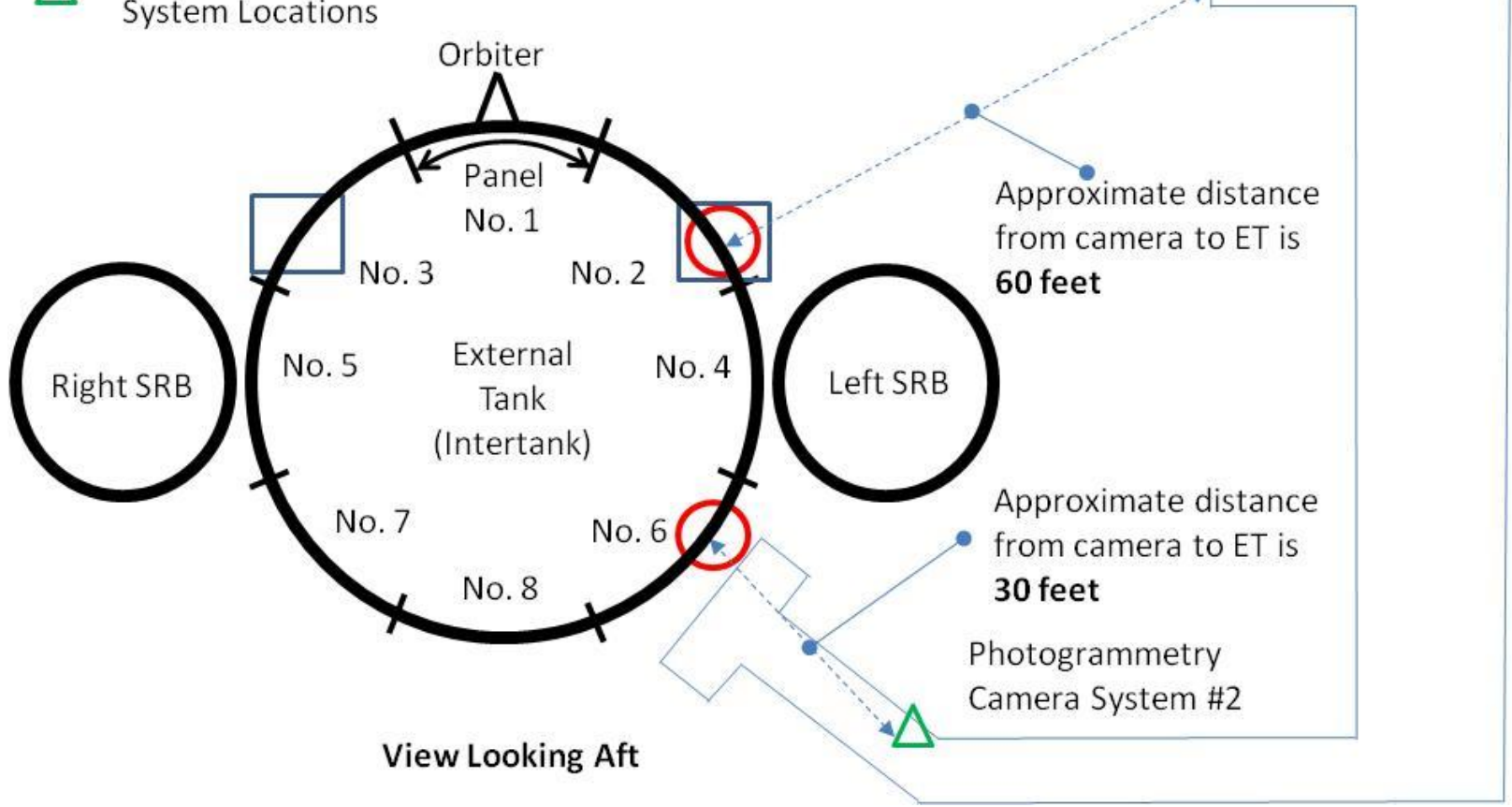

Figure 5. Tanking test set-up. 


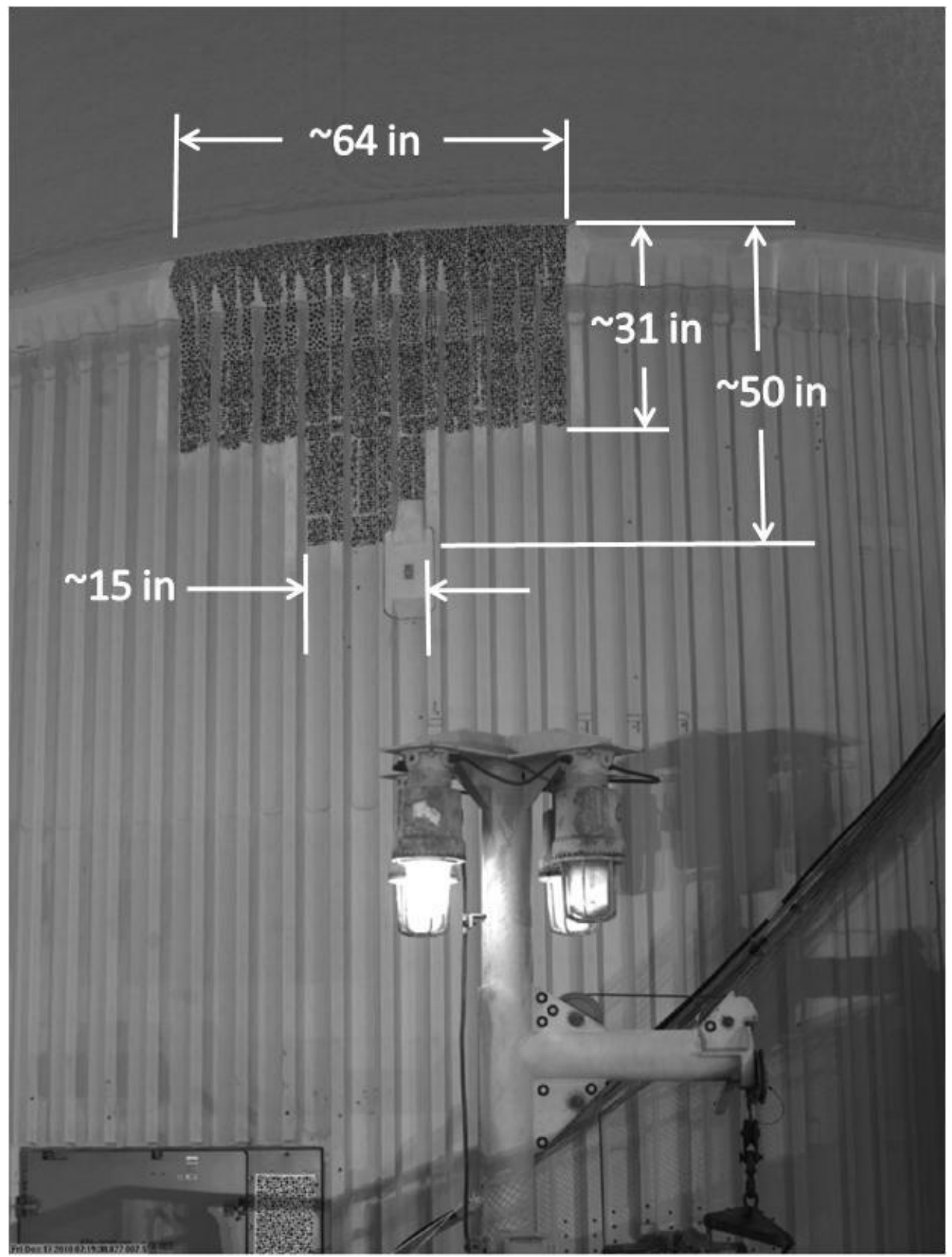

Figure 6. Dimensions of speckle pattern applied to panel 6. 


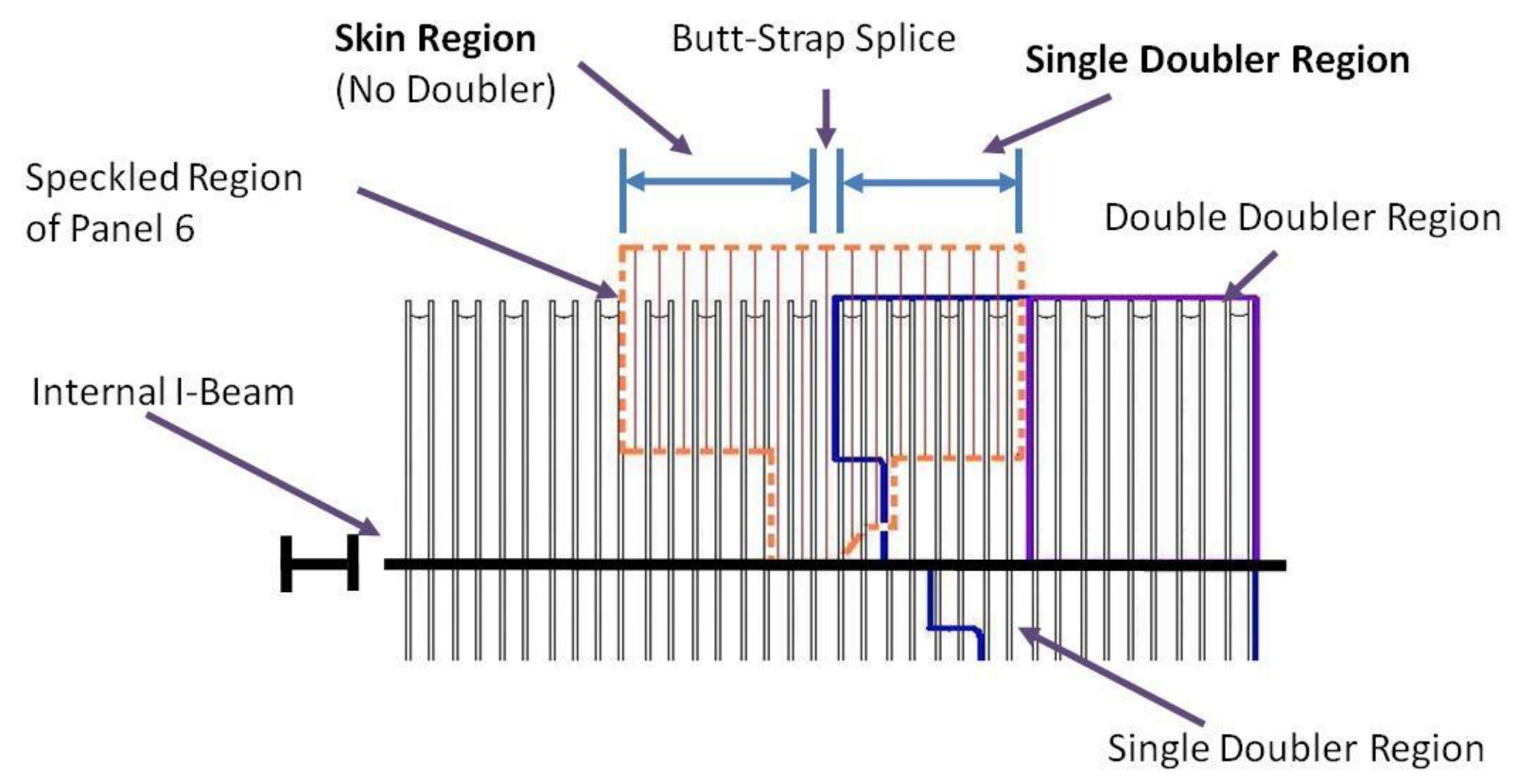

Figure 7. Speckle pattern of panel 6 with Intertank's underlying structure.

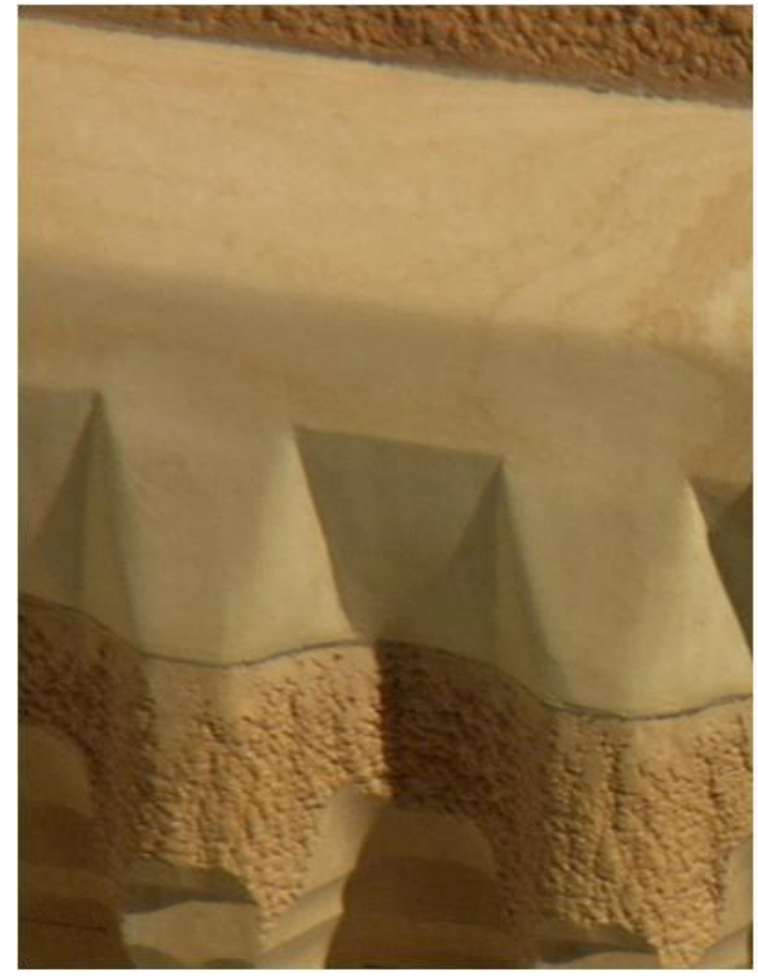

(a)

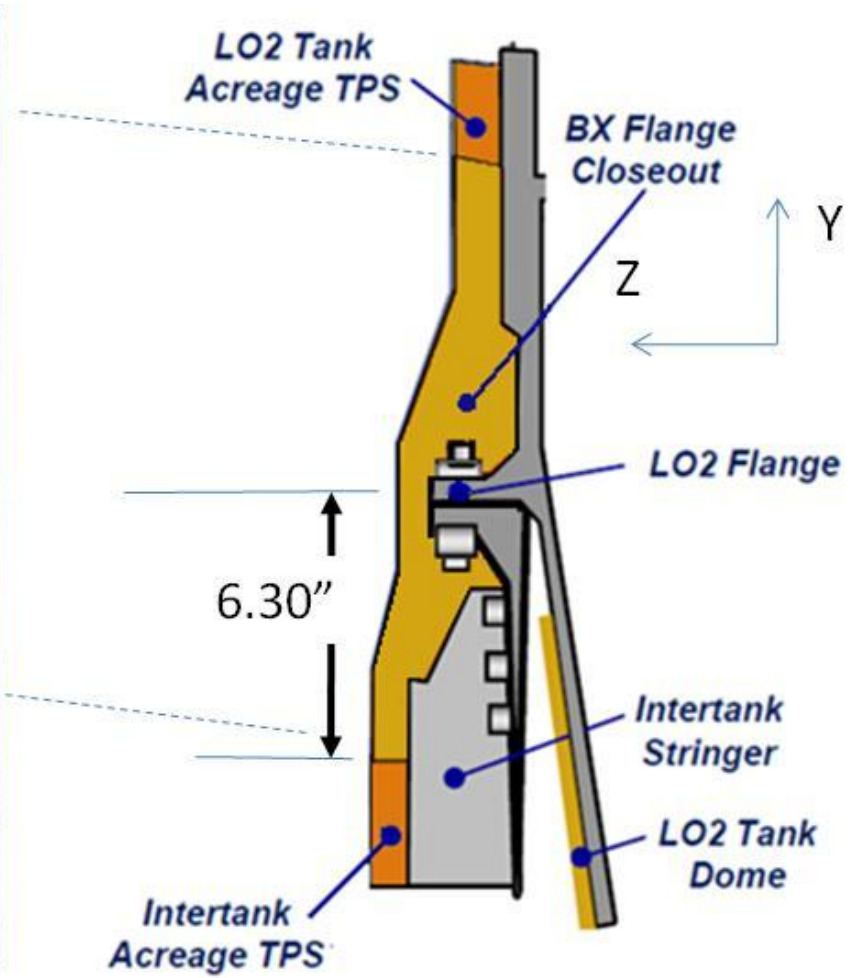

(b)

Figure 8. (a) TPS close-out photograph and (b) cross section schematic. 


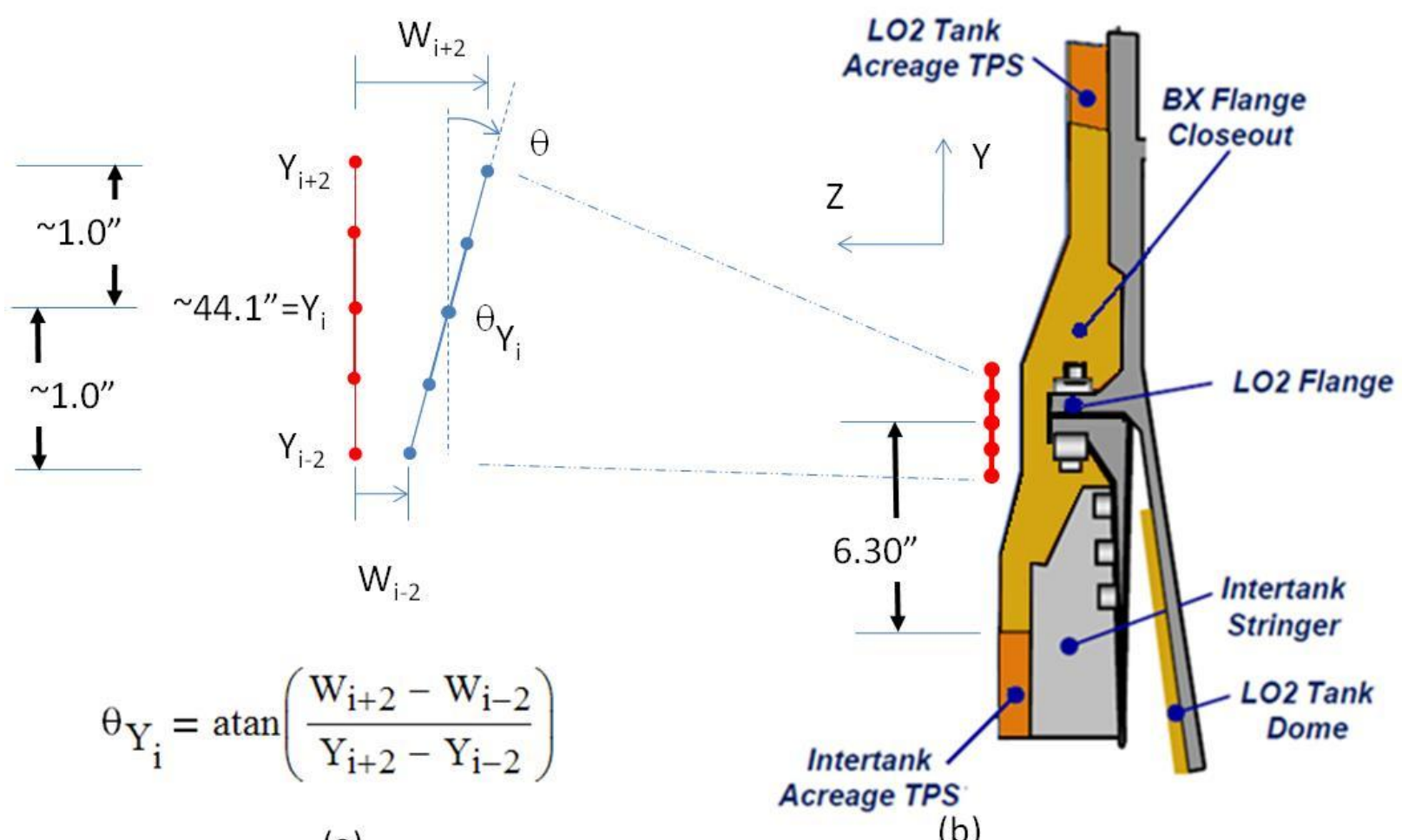

(a)

(b)

Figure 9. (a) Rotation computation for LO2 flange and (b) cross section schematic with corresponding region of interest highlighted. 


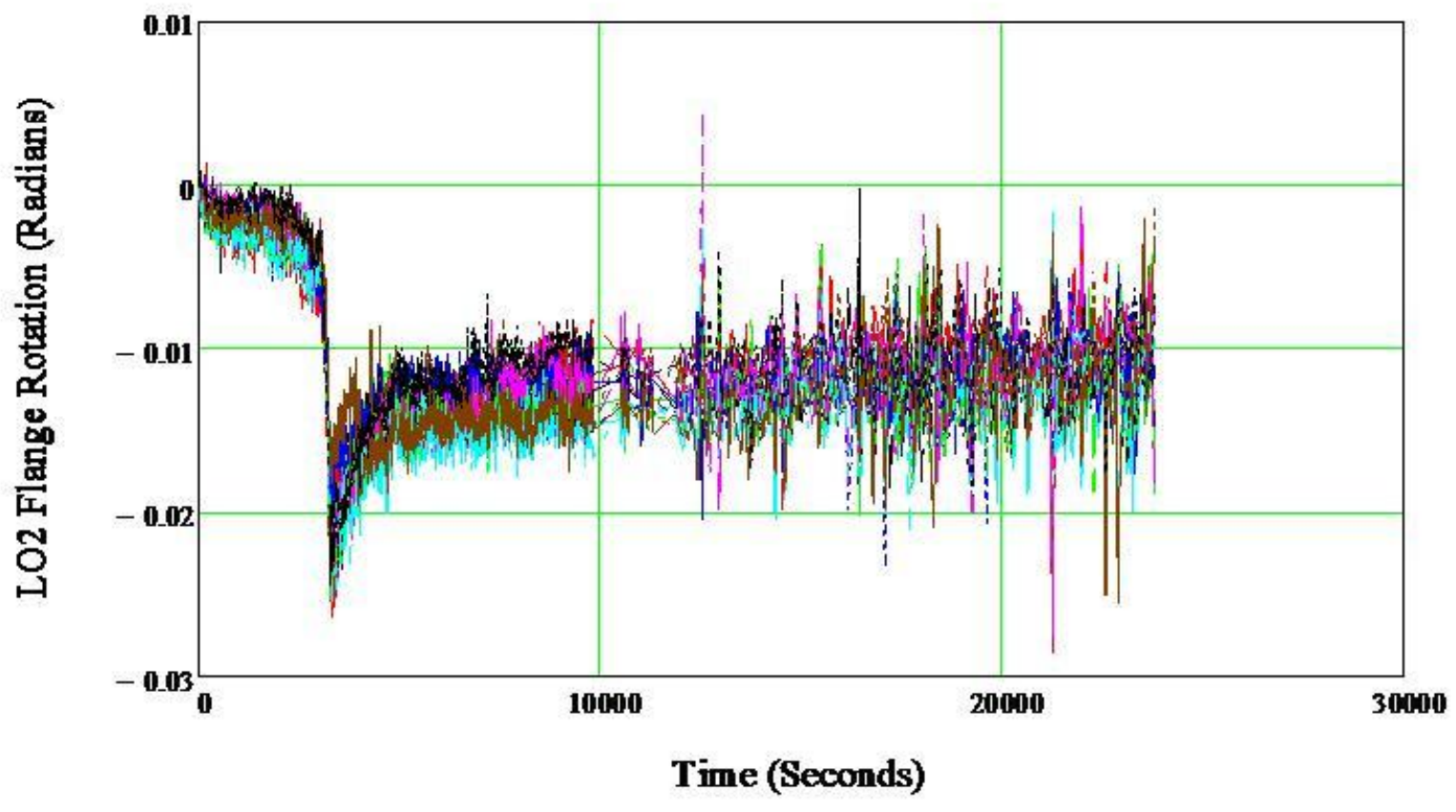

Figure 10. Flange rotation result (14 of 16 lines).

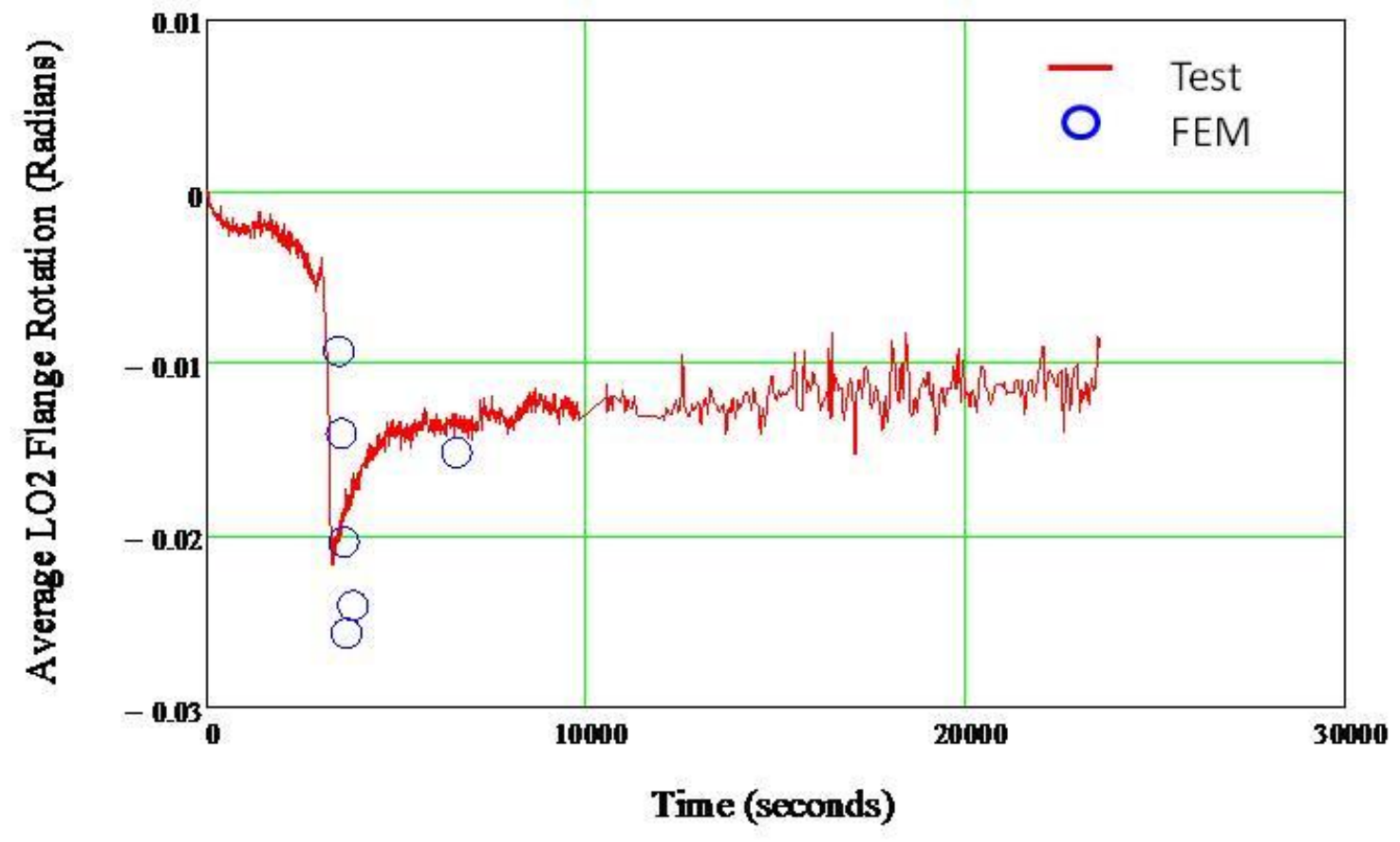

Figure 11. Average of flange rotation compared to FEM results. 


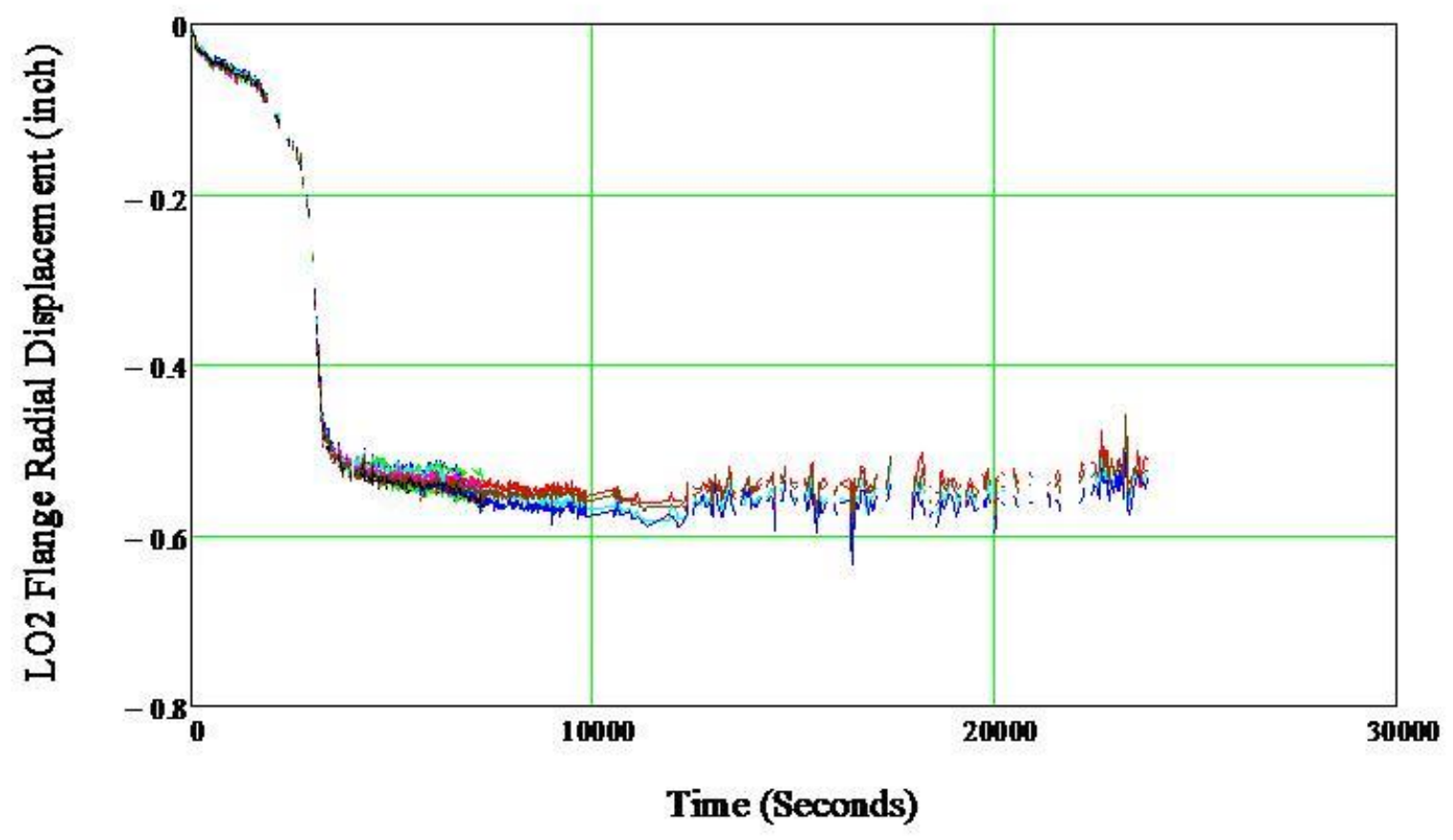

Figure 12. Flange radial displacement result (14 of 16 lines).

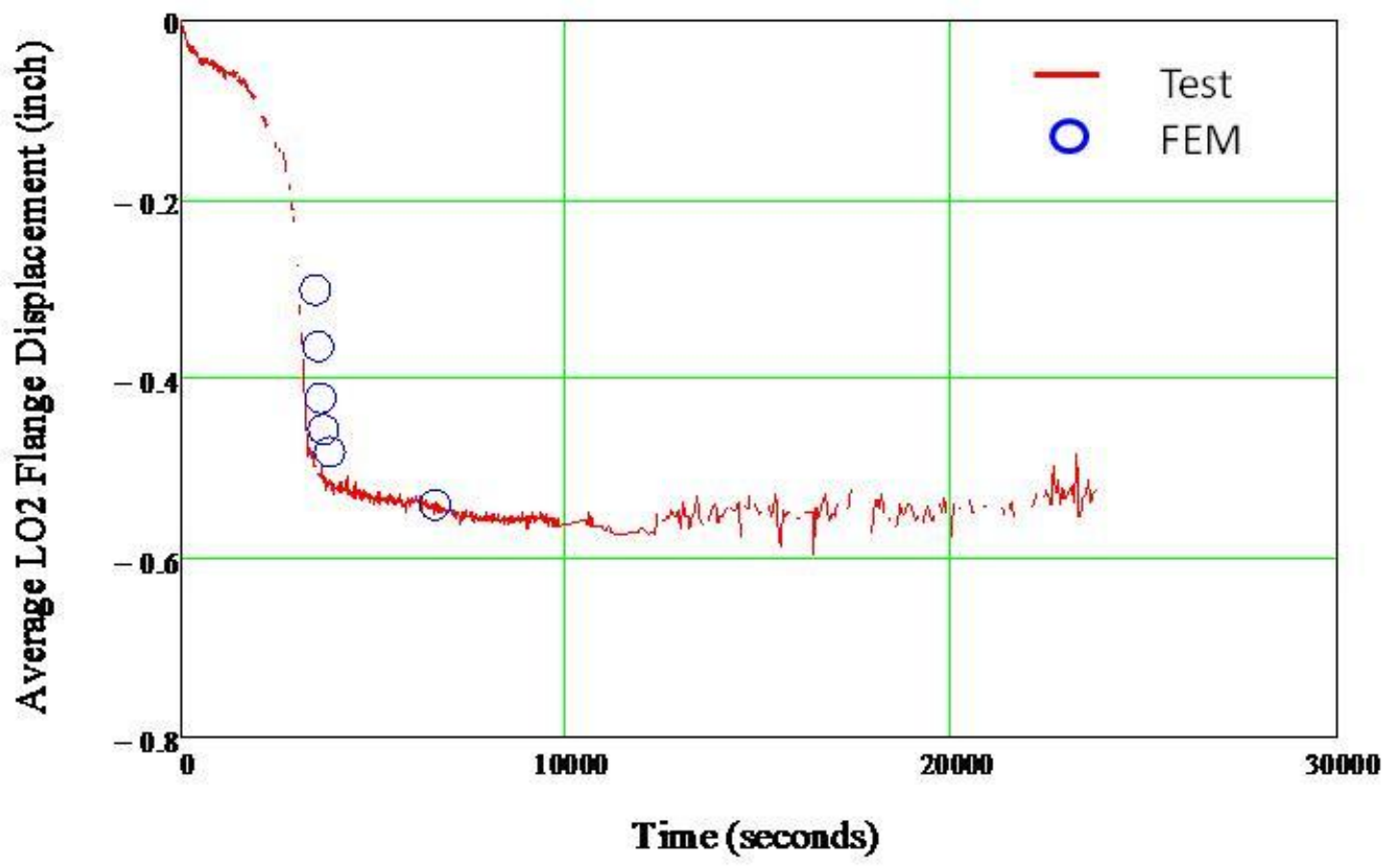

Figure 13. Average flange radial displacement compared to FEM results. 


\title{
STS-133/ET-137 Tanking Test Photogrammetry Assessment
}

\author{
Stanley T. Oliver ${ }^{1}$ \\ NASA Marshall Space Flight Center, Huntsville, AL
}

\begin{abstract}
On November 5, 2010, the launch of Space Shuttle Discovery on mission STS-133 was scrubbed due to a hydrogen gas leak at the ground umbilical connection to the External Tank, ET-137. In addition, an unrelated visual inspection of the External Tank's thermal protection system revealed a crack, which presented itself in a form never seen before, at the top of the Intertank near the liquid oxygen tank. Compounding the issue, it was discovered through dissection that the crack in the thermal protection foam was due to cracks in the Intertank's metallic stringers hidden beneath the foam. A large effort to understand and remedy these issues was immediately initiated. One important investigation was the instrumented tanking test which incorporated photogrammetry assessments of two relatively small regions, one where the thermal protection system crack occurred and another in a similar, yet un-cracked region. This test offered a unique and challenging opportunity, for the first and only instance in the long history of the Space Shuttle program, to interrogate with photogrammety the cryogenically induced deformations of the Intertank-liquid oxygen tank interface flange region. The photogrammetry systems witnessed the entire nine hour prelaunch tanking/detanking timeline, and the post-test assessment offered insight into the deformation and rotation history of the $\mathrm{LO} 2$ flange. The assessment of the deformation data produced valuable information that ultimately supported the development of flight rationale for ET-137. The photogrammetry results and correlation to finite element analysis results presented herein provide a synopsis of a complex scenario in which the LO2 flange displacement and rotation were strongly influenced by the liquid oxygen fluid level in the LO2 tank and that the worst-case flange rotation occurred when the fluid level just passed the $\mathrm{LO2}$ flange during the filling process.
\end{abstract}

\section{Introduction}

$\mathrm{F}$ OLLOWING the launch scrub of Space Shuttle mission STS-133 on November 5, 2010, an anomalous condition of cracked and raised thermal protection system (TPS) foam was observed on the External Tank (ET). Subsequent dissection of the affected TPS region revealed cracks in the feet of two Intertank (IT) metallic hat stringers. An extensive investigation into the cause(s) and corrective action(s) for the cracked stringers was initiated, involving a wide array of material and structural tests and nondestructive evaluations, with the intent to culminate into the development of flight rational ${ }^{1}$. One such structural test was the instrumented tanking test performed on December 17, 2010. In addition to the strain and temperature measurements, the tanking test incorporated two threedimensional optical displacement measurement systems to measure full-field outer surface displacements of the TPS. One system was dedicated to the repaired region that contained the initial stringer cracks, and for comparison, another system was dedicated to an as-built region with similar structural features. The photogrammetry assessment results showed that the radial displacement and rotation of the liquid oxygen (LO2) tank flange changed significantly as the fluid level of the LO2 approached and passed the LO2 tank flange.

\section{Background}

In this section, structural design features of the ET are described, narrowing to the details specific to the region near the stringer cracks. Following the ET descriptions, the goals of the tanking test are listed and the photogrammetry system setup is briefly described. Lastly, the dimensional coverage of the photogrammetry speckle pattern is provided as well as the important underlying structure configuration beneath the speckle pattern and TPS.

\footnotetext{
${ }^{1}$ Aerospace Engineer.
} 


\section{A. External Tank Design}

The Space Shuttle flight vehicle, an assembly of an Orbiter, two Solid Rocket Boosters (SRBs), and the ET, is shown in Fig. 1. A box with an ' $X$ ' in Fig.1 marks the approximate location of the cracked stringer on ET-137. The ' 137 ' is the production order number for the ET. An expanded view of the ET in Fig.2 shows the three primary structural components of the ET, the liquid hydrogen (LH2) tank, LO2 tank, and IT. Figure 3 shows a general view of the IT, with the forward (flight) direction identified as well as the identification a single thrust panel and hatstiffened skin-stringer panel. Also shown in this general view of the IT are three of five circumferential ring frames inside the IT. Two diametrically opposed thrust panels receive and distribute the SRB loads. The thrust panels are single piece integrally machined panels. These two thrust panels plus six skin-stringer panels are mechanically joined to form the unpressurized IT. Figure 4 shows the basic construction of a typical skin-stringer panel. The hatstringers span the full length of the IT except in locations where they would interfere with a large penetration. The forward and aft ends both have an L-shaped bolting flange to join to the LO2 and LH2 tanks respectively. Also shown are skin doublers, which are extra skin layers for increased strength. The cracked feet were at the forward end of the stringers, shown in the right-hand side of Fig. 4. The TPS was sprayed over the IT and LO2 tank, completely covering the stringers, skin, bolting flanges, and LO2 tank.

\section{B. Tanking Test}

The dissection of the affected TPS region of panel 2 revealed cracks in the feet of two IT metallic hat stringers (S6-2 \& S7-2). The cracked length of the two affected stringers were replaced with a standard repair, which included a new stringer portion, splice joint, and the addition of radius blocks on the feet of the stringers. Video evidence of the launch scrub narrowed the time of occurrence of the cracked TPS and therefore, the stringers, to when the liquid oxygen in the LO2 tank was near the LO2 flange. Therefore, to expose the repaired stringers to this same thermal environment, a tanking test was performed. The tanking test sequence followed the standard pre-launch propellent loading procedures and time-line.

The region of the stringer repair on panel 2 was instrumented with strain gages and thermocouples to (1) ascertain the presence of any unforeseen structural design issues of the repair and (2) assist in grounding analysis models ${ }^{2}$. In addition, a similar instrumentation package was applied to panel 3 , an unrepaired site of similar structural geometry, to facilitate collection of direct comparative data between repaired and as-built structural response to thermal environments.

A comparative assessment between panel 2 (representing the repaired region) and panel 6 (representing the asbuilt region) was also planned using three-dimensional optical displacement measurement systems, or photogrammetry. The radial displacement of the IT and LO2 tank as the LO2 approached and passed the LO2 flange was of particular interest; therefore, photogrammatic speckle patterns were applied to the outer surface of the TPS near the LO2 flange.

\section{Photogrammetry}

The photogrammetry camera systems (ARAMIS 3D Image Correlation Systems) were mounted to the Launch Complex 39A Fixed Support Structure (FSS). The camera system used to image the repaired region of panel 2 was sixty feet away. The camera system used to image the as-built region of panel 6 was thirty feet away. An over-head sketch of the ET, two SRBs, and the FSS is shown in Fig. 5. The eight IT panels, the location of the two photogrammetry camera systems and their distance from the ET, and the instrumentation and photogrammatic speckle pattern locations are also shown. For more imformation on the photogrammetry aspects of the tanking test, including set-up, calibration, operational challenges, and results, refer to Ref. 3.

The photogrammetry system used to image the repaired region of panel 2 lost its calibration and did not yield reliable deformation results. The photogrammetry system used to image the as-built region of panel 6 remained in calibration throughout the duration of the test and provided useful displacement data. The comparative assessment between the two panels could not be performed; however, the displacement results from panel 6 provided valuable data to assess. The analyses, results and conclusions presented herein pertain only to panel 6.

The dimensions of the T-shaped photogrammetry speckle pattern applied to panel 6 are shown in Fig. 6 . A width of sixty-four inches at its widest and fifty inches at its tallest, the speckle pattern covered approximately 2270 square inches or less than 16 square feet, a relatively small area compared to the ET. The structure of panel 6 in relation to the speckle pattern is shown in Fig. 7. The eighteen stringers of panel 6 are shown as well as the single and double skin doubler regions. No portion of the speckle pattern was over the double-doubler region, the pattern only covered portions of the basic (no doubler) skin-stringer region and the single doubler region. The top of the speckle extended slightly above the Intertank/LO2 tank mating flange. A coordinate frame is positioned near the bottom-center of the speckle pattern, with the $\mathrm{X}$-axis as horizontal or hoop, Y-axis as vertical or axial. The Z-axis is the out-of-plane 
coordinate, but not shown in the figure. Also shown in Fig. 7 is the location of the internal circumferential ring frame. Lastly, sixteen lines equally spaced across the width of the speckle pattern are shown. These lines are located on the stringer tops and stringer valleys, and represent the locations where radial displacement data from the photogrammetry system was analyzed.

\section{Analysis}

The photogrammetry system captured images throughout the entire test, from just prior to the beginning of LO2 fill until the LO2 tank had nearly been drained. The time span from first image to last is greater than nine hours. A total of 1637 images were captured, with the following frequencies:

1) Every 10 seconds during fill (for approximately 175 minutes)

2) Every 60 seconds during stable replenish (for approximately 240 minutes)

3) Every 6 seconds during pre-pressurization (for approximately 12 minutes)

4) Every 10 seconds during drain (for approximately 28 minutes)

5) Every 60 seconds during remainder of drain (for approximately 105 minutes).

This assessment investigated the radial displacement data from the photogrammetry system. ARAMIS postprocessing output files were in the form of data extraction time history along each line of interest for each image. Data extraction was the Y-coordinate and three displacement components, but only the out-of-plane (considered radial) was investigated for this paper. The displacement data was studied along the stringer tops and valleys along sixteen vertical lines that extend from top to bottom of the speckle region, with emphasis on the radial contraction and rotation of the LO2 flange. The key assumption for the analysis is that the TPS movement closely follows that of the metallic components under the TPS and that any differential movement of the TPS due to thermal is small relative to the overall deformations of the $\mathrm{LO} 2$ tank and Intertank.

\section{A. LO2 Flange Location}

The LO2 flange was obscured by the TPS, which made it difficult to locate the Y-coordinate of the flange beneath the speckled region. However, design drawings of the LO2 flange TPS close-out indicate that the mating surface between the LO2 and IT flange is 6.30 inches above the intersection of the IT acreage and LO2 flange closeout TPS applications ${ }^{4}$. This intersection is clearly visible in a photograph of the flange TPS close-out shown in Fig. 8(a). The lighter colored TPS in the center of the photograph is the LO2 flange TPS close-out, while the darker colored TPS covers the LO2 tank and IT acreage. Within ARAMIS, the intersection was also clearly visible and could be used to interrogate its Y-coordinate. The Y-coordinate of the Intertank to LO2 flange was determined to be 44.1 inches in the coordinate system shown in Fig. 7. Figure 8(b) shows a cross sectional schematic of the LO2 flange region, showing the LO2 and IT metallic components and the TPS coverage. Dotted lines between Fig.8(a) and Fig. 8(b) link the TPS intersections shown in the photograph and schematic. Also identified is the 6.30 inch dimension between the LO2 and IT flange interface and LO2 flange close-out TPS application.

\section{B. LO2 Flange Rotation and Displacement}

The LO2 flange rotation computation methodology used an inverse trigonometric relationship, relating the rotation $(\theta)$ to the change in out-of-plane displacements (W) and Y-coordinates (Y). This approach inherently accounts for rigid body motion since it considers changes in position. Figure 9(a) shows the methodology for calculating the rotation at the data point closest to the LO2 flange, $\mathrm{Y}_{\mathrm{i}}$. Rotation is based on the Y-coordinates and corresponding out-of-plane displacement (W) of two data points, one above and one below the flange, skipping the two data points nearest to $\mathrm{Y}_{\mathrm{i}}$. Ignoring the (i+1) and (i-1) data points tended to smooth the rotation data. Figure 9(b) shows a cross section schematic depicting the LO2 flange region and the approximate range of the photogrammetry data used in the calculation of the rotation.

LO2 flange radial displacements were read directly from the results file at a point nearest to $\mathrm{Y}=44.1 \mathrm{inch}$. However, this displacement includes the rigid body motion of the Shuttle stack moving towards or away from the cameras. The forward-most Intertank ring frame, shown in Fig. 3 and schematically in Fig. 7, offers a radially stiff location and is far enough removed from the temperature gradients that any movement may be considered rigid body motion. Therefore, to remove the radial rigid body motion component of displacement at the LO2 flange, the displacements were grounded or subtracted from the radial motion of the IT internal frame.

Although the data collection during the tanking test was from beginning of the fill until the LO2 tank had nearly been drained, the primary focus for this paper was when the LO2 fluid level approached and passed the LO2 flange. The first 650 images were analyzed, representing a time line from beginning of the test until the LO2 tank was approximately one-half full. This was the first 7000 seconds of the tanking test, or approximately $20 \%$ of the test 
duration. Figure 10 shows three approximate fluid levels in the LO2 tank, labeled $A, B$, and $C$, and their corresponding time in seconds during the test. These three fluid levels represent special times of interest during the tanking test. The lowest most fluid level represents the 5\% fill level the LO2 tank. The middle fluid level is very near the level of the LO2 flange and represents a time equivalent to when the stringer cracked during the initial fill. The highest fluid level represents a time in which the instrumentation from the tanking test was at steady-state. These three fluid level lines in Fig. 9 are also presented in the results section to provide correlation between time and fluid levels.

\section{Results}

The computed LO2 flange rotation results are shown in Fig. 11, showing the flange rotation as a function of time for fourteen of the sixteen stringer/valley lines. Two lines were omitted due to missing data in the area of interest. As the LO2 filled the lower portion of the LO2 dome (fluid level $A$ ), the flange began to slowly rotate due to the thermal gradients within the LO2 tank and IT. As the LO2 fluid level approached and passed the LO2 flange (fluid level $B$ ), a sharp increase in flange rotation was observed. As the thermal gradients transitioned to steady-state the rotation angle relaxed to its steady-state position (fluid level $C$ ). The average of the fourteen lines is shown in Fig. 12. Also shown in Fig. 12 are diamond-shaped markers that represent finite element results using a single stringer finite element model $^{5}$.

The radial displacement of the LO2 flange was also of interest. The resulting LO2 flange displacement as a function of time is shown in Fig. 13. Similar to the LO2 flange rotation assessment, the radial displacement began small and then suddenly increased as the LO2 fluid level approached the LO2 flange. However, unlike the rotation, the displacements did not relax, but maintained their value through steady-state. The average displacement data is shown in Fig. 14 which also contains diamond-shaped markers representing the finite element displacement results ${ }^{5}$.

\section{Conclusions}

Following the November 5, 2010 launch scrub of Space Shuttle mission STS-133, an anomalous condition of cracked and raised thermal protection system (TPS) foam was observed on the External Tank (ET). Subsequent dissection of the affected TPS region revealed cracks in the feet of two Intertank (IT) stringers. On December 17, 2010, to test the stringer repairs, an instrumented tanking test was performed incorporating three-dimensional optical displacement measurement systems to measure full-field outer surface displacements of the TPS. This unique and challenging test offered an opportunity to interrogate with photogrammety the cryogenically induced deformations of the Intertank-liquid oxygen tank interface region while it was subjected to pre-launch tanking procedures. The photogrammetry assessment of the tanking test concentrated on the angular rotation and radial deflection of the LO2 flange. It was determined that the displacements and rotation of the LO2 flange was strongly influenced by the fluid level of the liquid oxygen and the thermal gradients within both the LO2 tank and IT. As the fluid level approached the LO2 flange, the flange rotation and radial contraction were observed to change quickly. However, as the IT temperature profile approached steady-state, the flange rotation relaxed while the radial displacements maintained their position. These results confirmed the finite element predictions that the worst-case flange rotation was during the thermal transient phase as the fluid level of the LO2 approached and passed the LO2 tank flange.

\section{Acknowledgments}

The author would like to acknowledge Mr. Tim Schmidt of Trilion Quality Systems for his dedication and support provided to the STS-133 tanking test. Mr. Schmidt's expertise was crucial in the set-up and operation of the ARAMIS photogrammery systems as well as the post-processing of the ARAMIS data used in this analysis performed at the Marshall Space Flight Center.

The author would also like to acknowledge Mr. Brian Steeve of the Marshall Space Flight Center for the finite element results data to illustrate the correlation between the photogrammetry and analysis results.

The author encourages a review of J.D. Littell's paper (Ref. 3), which describes the challenges in setting up the test with only ten days notice. In addition, please review Littell's Acknowledgment section, to understand the great number of individuals, skills, and efforts required to perform photogrammetry on the STS-133 tanking test. 


\section{References}

${ }^{1}$ Anon., "STS-133 Delta Center Directors Pre-FRR, External Tank Project," Lockheed Martin Michoud Space Systems, February 7, 2011.

${ }^{2}$ Smith, R.,’STS-133/ET-137 Instrumented Tank Test Assessment of Strain-Gage Data”, Lockheed Martin Michoud Space Systems, Internal Report, 2011.

${ }^{3}$ Littell J.D. et al. "Photogrammetry Measurements During a Tanking Test on the Space Shuttle External Tank, ET-137", Proceedings from the Society of Experimental Mechanics Annual Conference. June 11-14, 2012. Costa Mesa, CA (to be published).

${ }^{4}$ Anon., "Foam Closeout-LO2 Tank Intertank STA 852.0, P/L BRKT STS 861.98, Aero Vents, 80971118414-510," Drawing, Sheet 31, Section A-A., Lockheed Martin Michoud Space Systems (2002).

${ }^{5}$ B. E. Steeve, "STS-133 Space Shuttle External Tank Intertank Stringer Crack Investigation Stress Analysis," paper accepted for presentation at the 53rd AIAA SDM Conference, Honolulu, HI, 23-26 April 2012, Paper No. TBD.

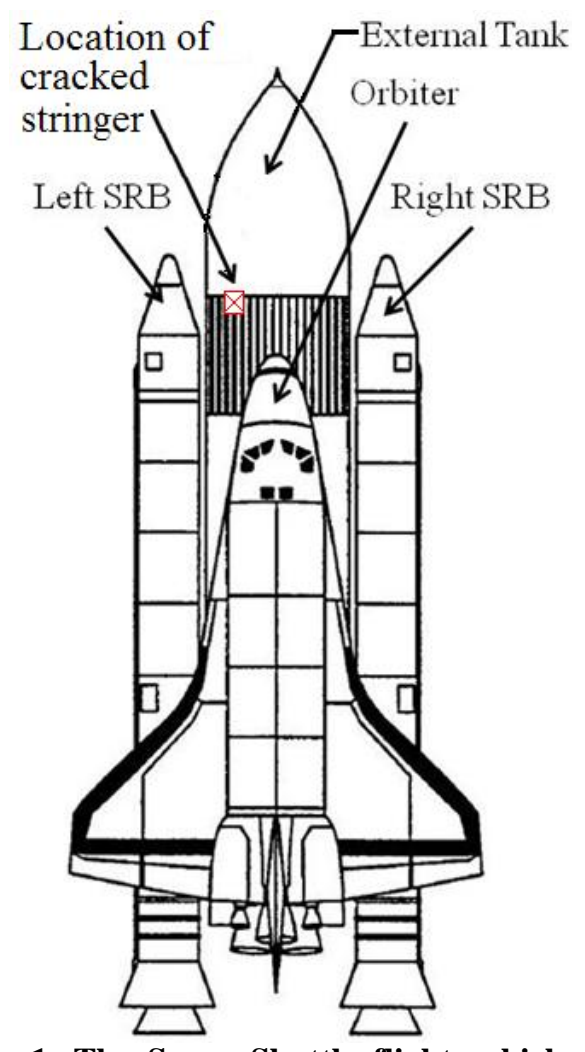

Figure 1. The Space Shuttle flight vehicle with the location of the cracked stringer identified.

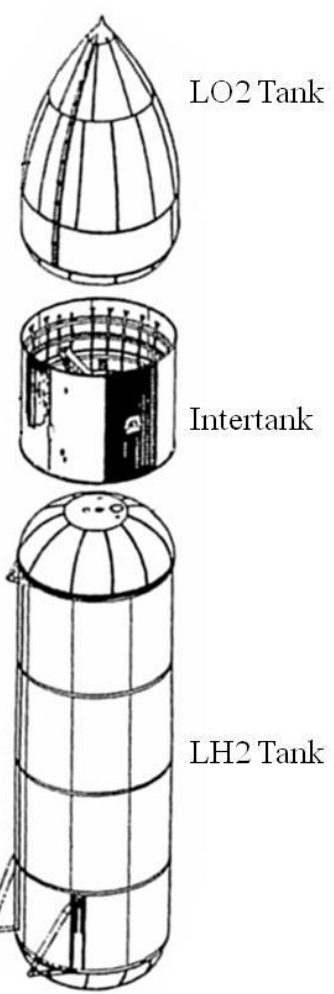

Figure 2. Expanded view of the External Tank's primary structural components.

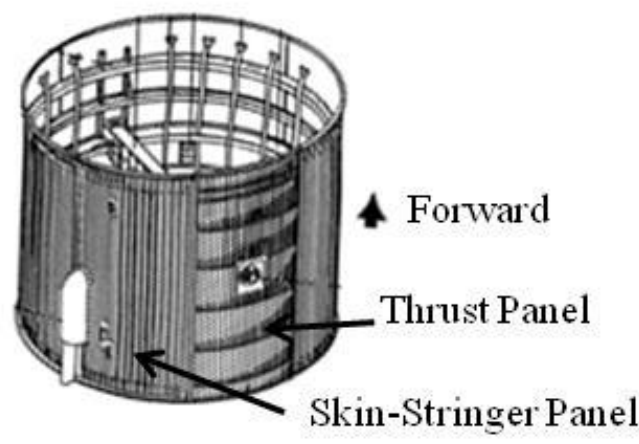

Figure 3. General view of the ET's Intertank. 


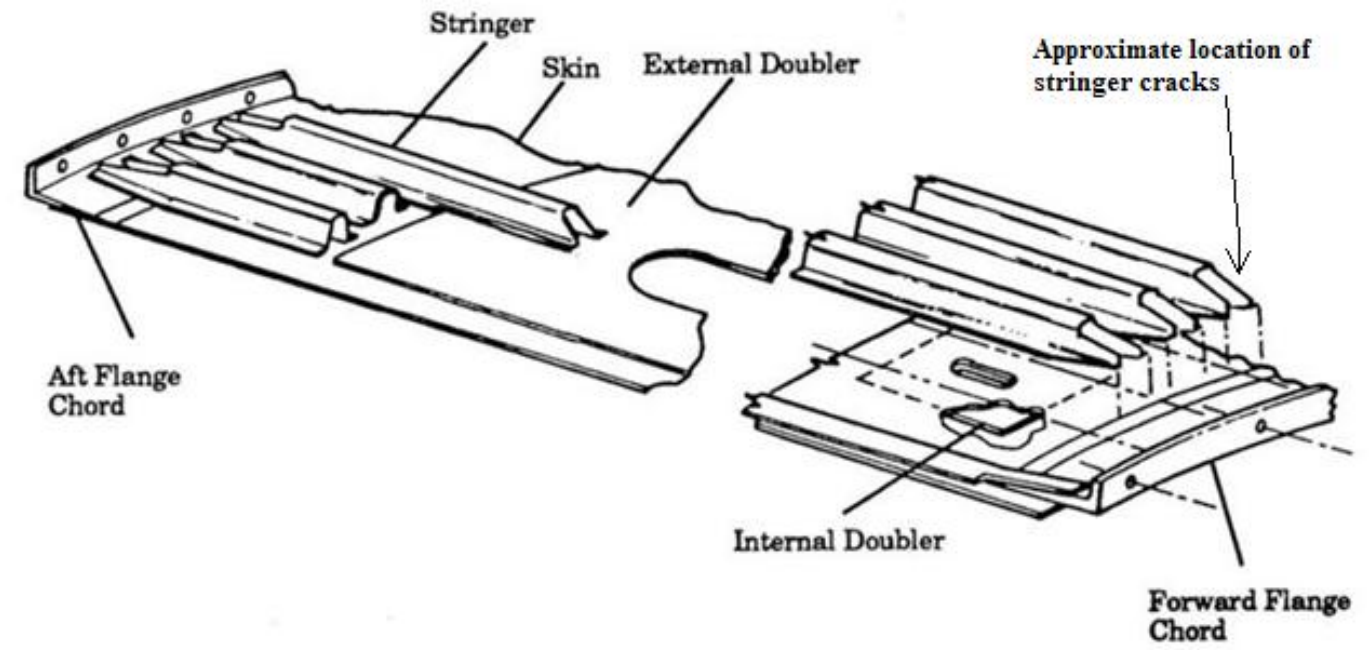

Figure 4. Basic construction of Intertank skin-stringer panel.

Forward Flange
Chord

Strain gage and

Thermocouple Locations

$\bigcirc$

Photogrammetry Speckle

Pattern Locations

$\triangle$ Photogrammetry Camera

System Locations

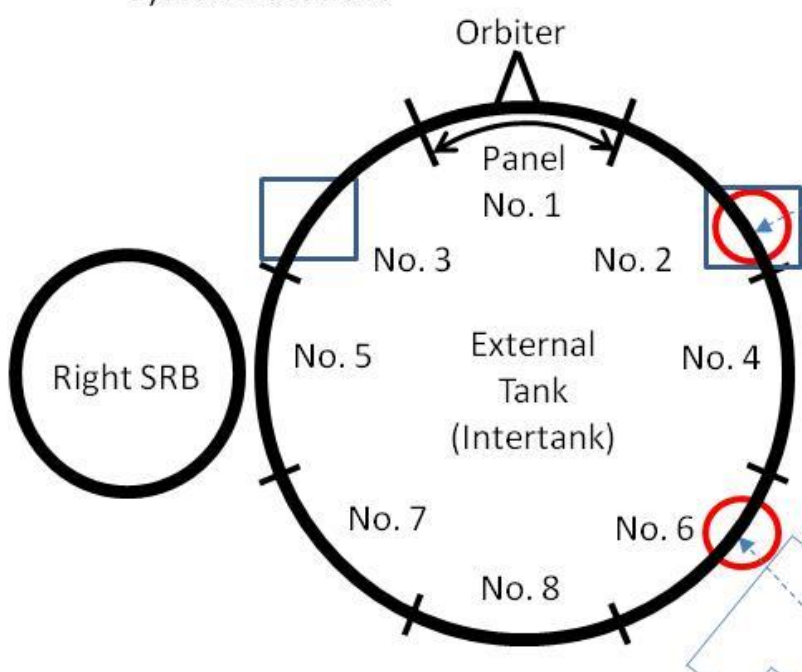

View Looking Aft

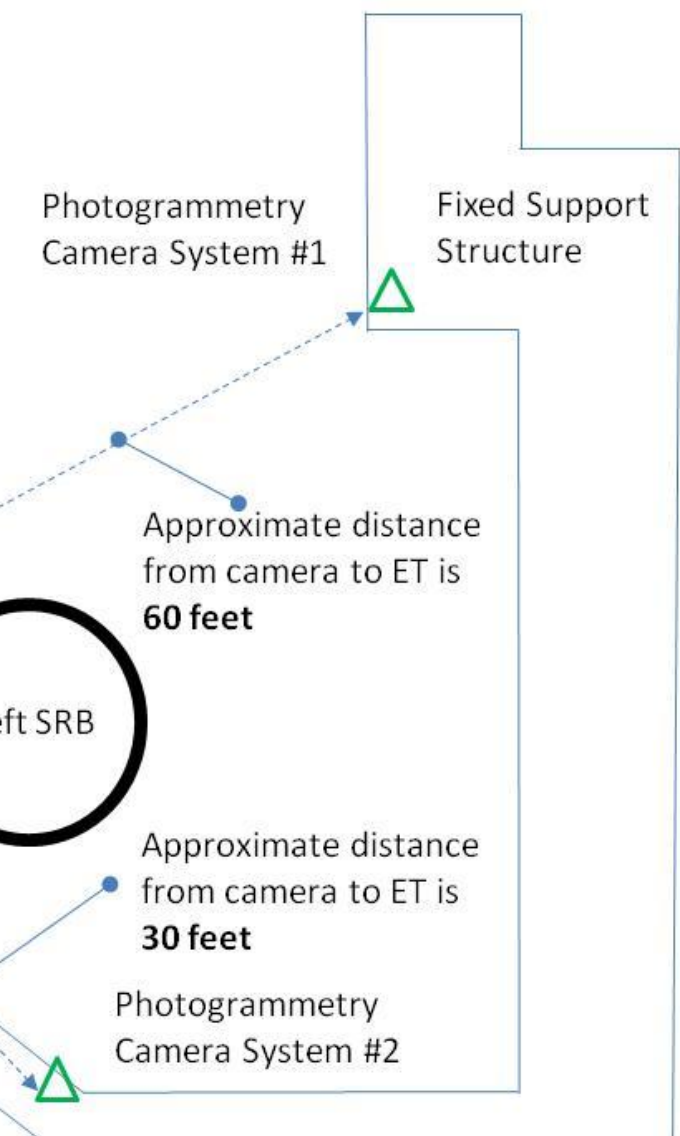

Figure 5. A view looking aft of the tanking test setup on the Shuttle relative to the Fixed Support Structure.

American Institute of Aeronautics and Astronautics 


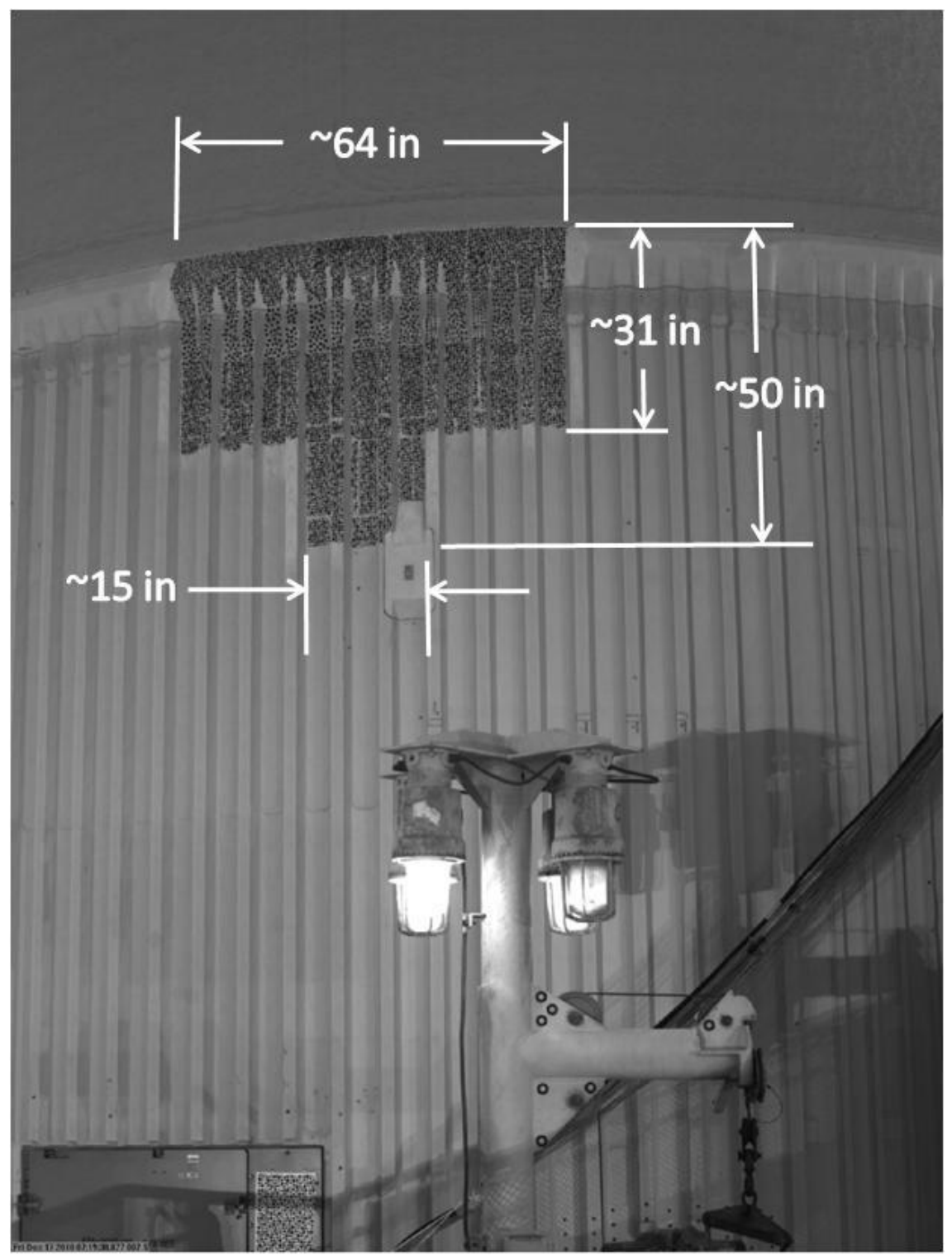

Figure 6. Dimensions of the T-shaped speckle pattern applied to panel 6. 


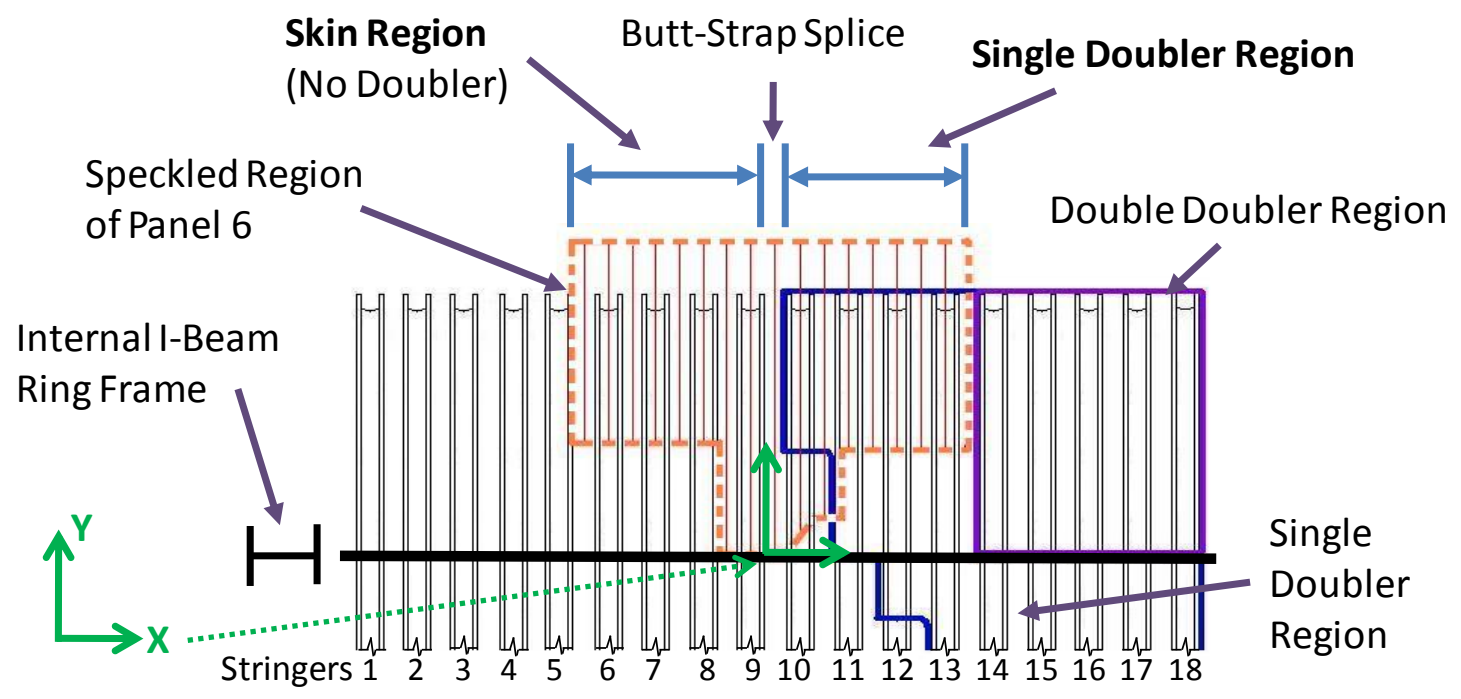

Figure 7. Speckle pattern of panel 6 with the Intertank's underlying structure.

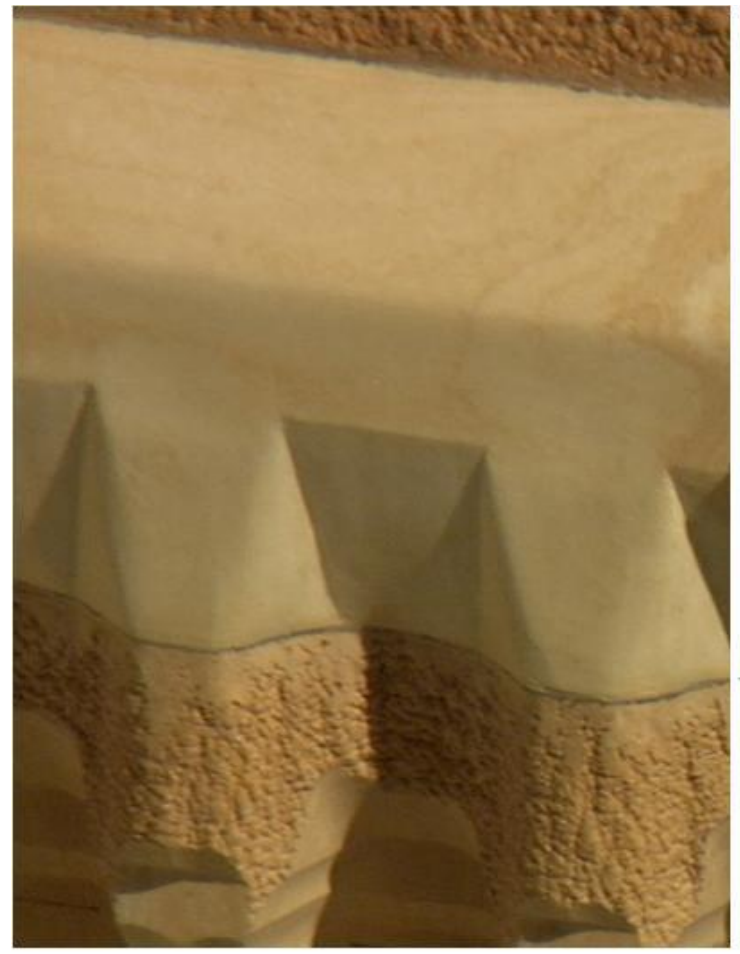

(a)

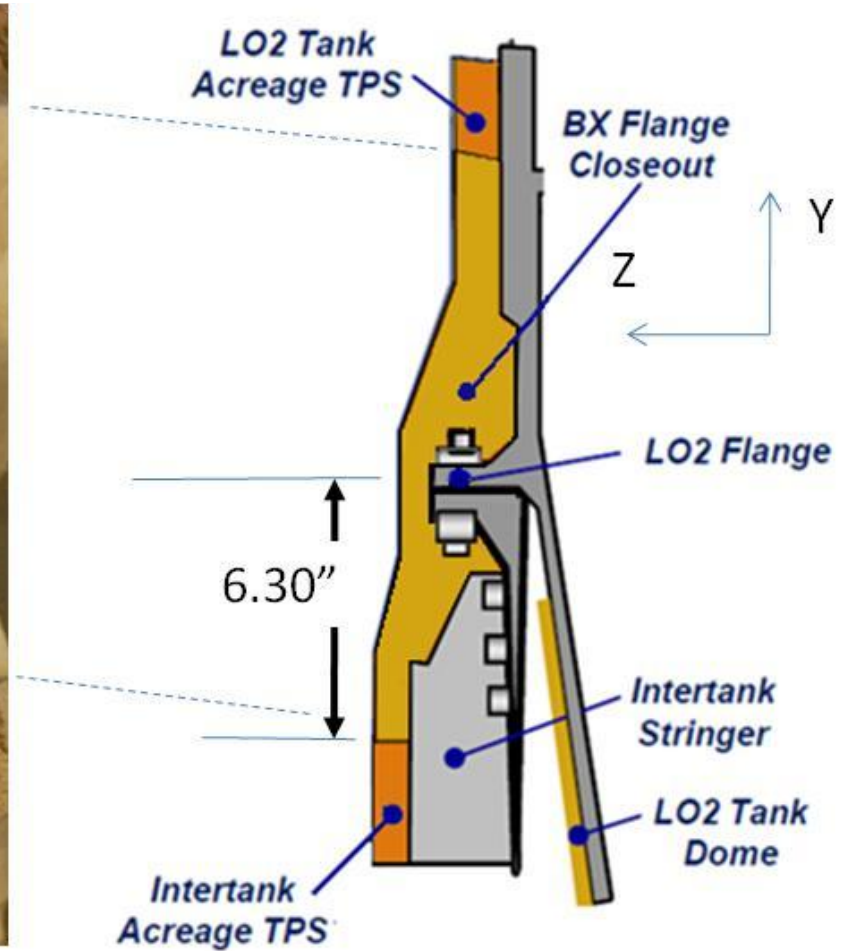

(b)

Figure 8. (a) TPS close-out photograph and (b) cross section schematic. 


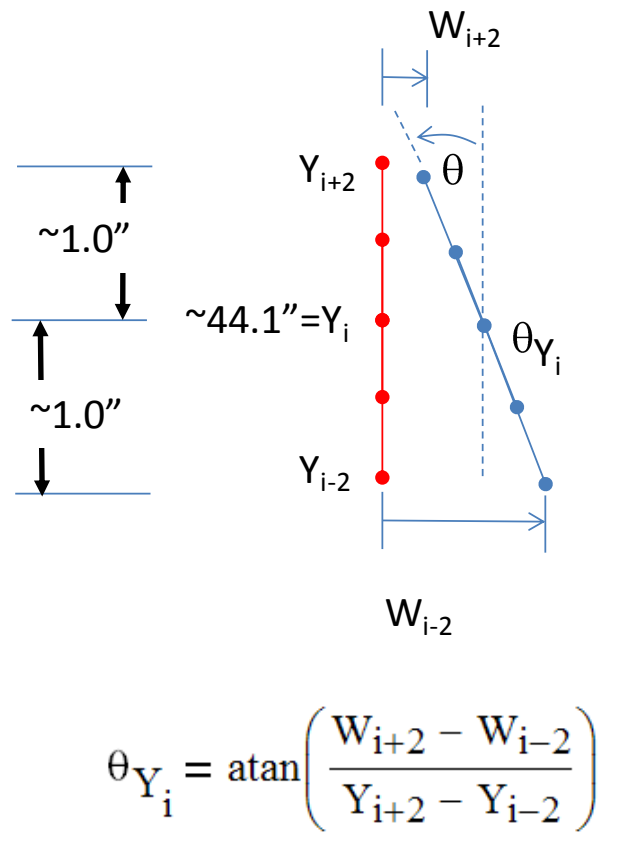

(a)

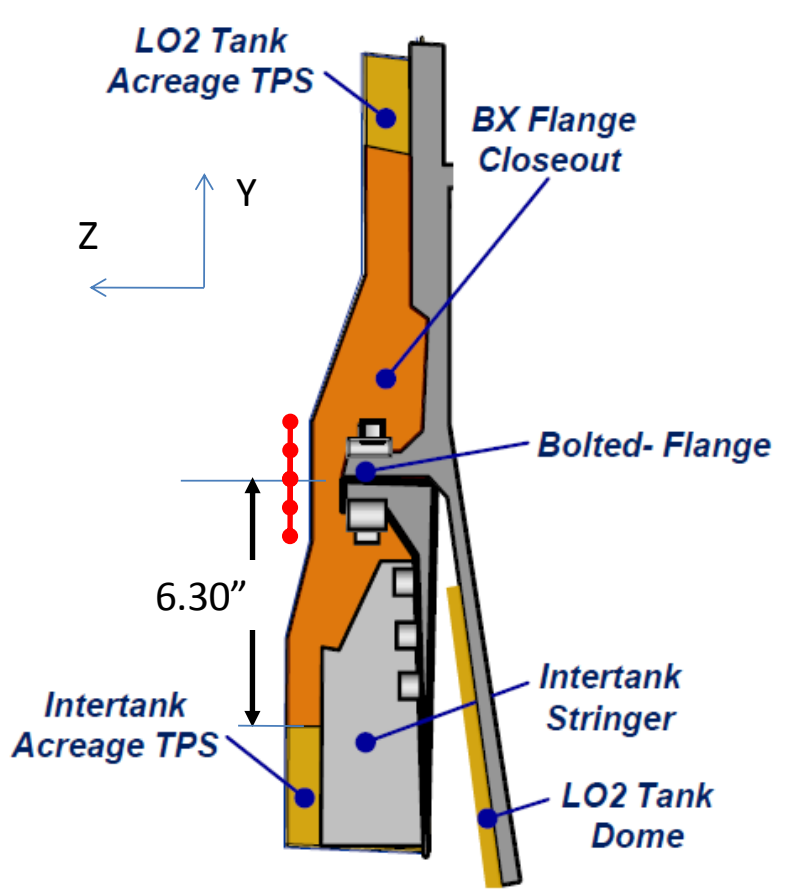

(b)

Figure 9. (a) Rotation computation methodology for LO2 flange and (b) cross section schematic with corresponding approximate location of data points of interest from photogrammetry data lines.

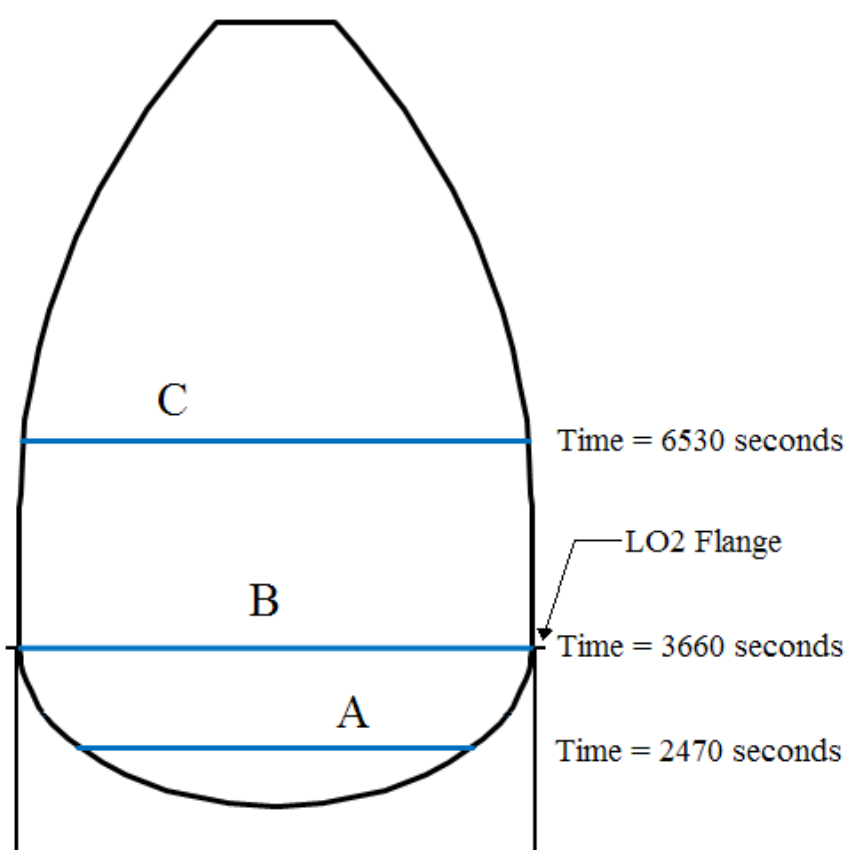

Figure 10. A side view of LO2 tank showing the location of the LO2 flange and three fluid levels with corresponding times of interest during tanking test. 


\section{LO2 Flange Rotation vs. Time}

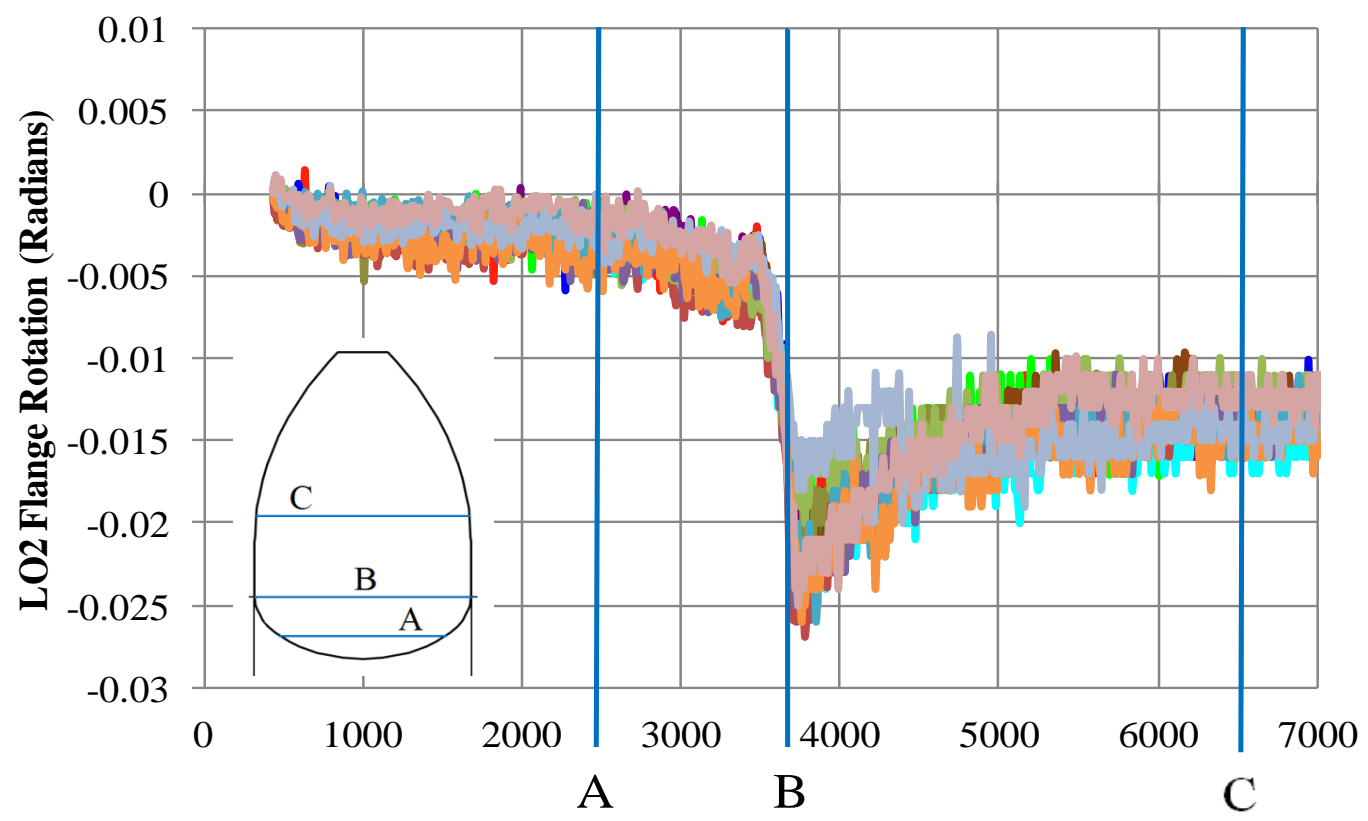

Time (seconds)

Figure 11. Flange rotation results (14 of 16 lines).

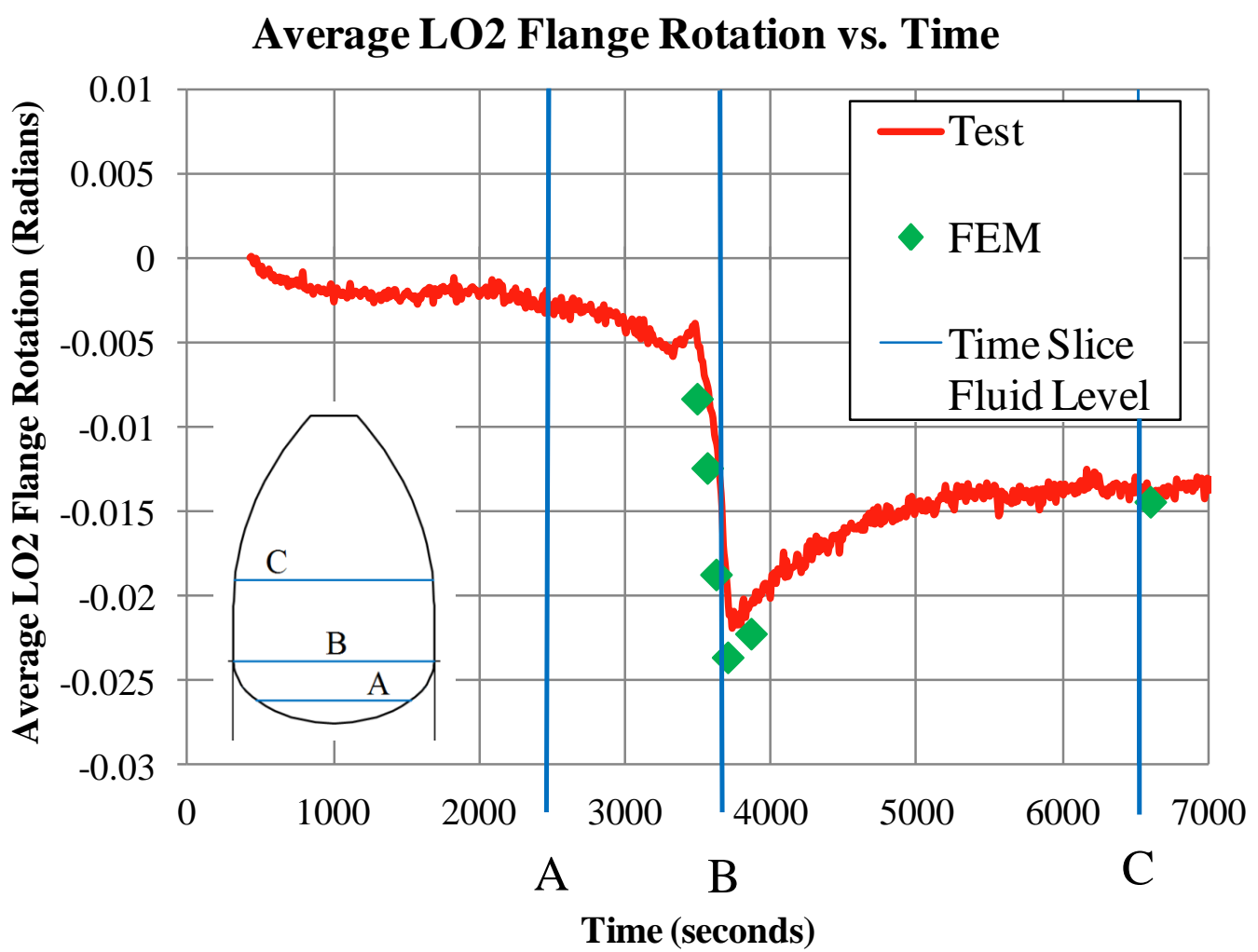

Figure 12. Average of flange rotation compared to FEM. 


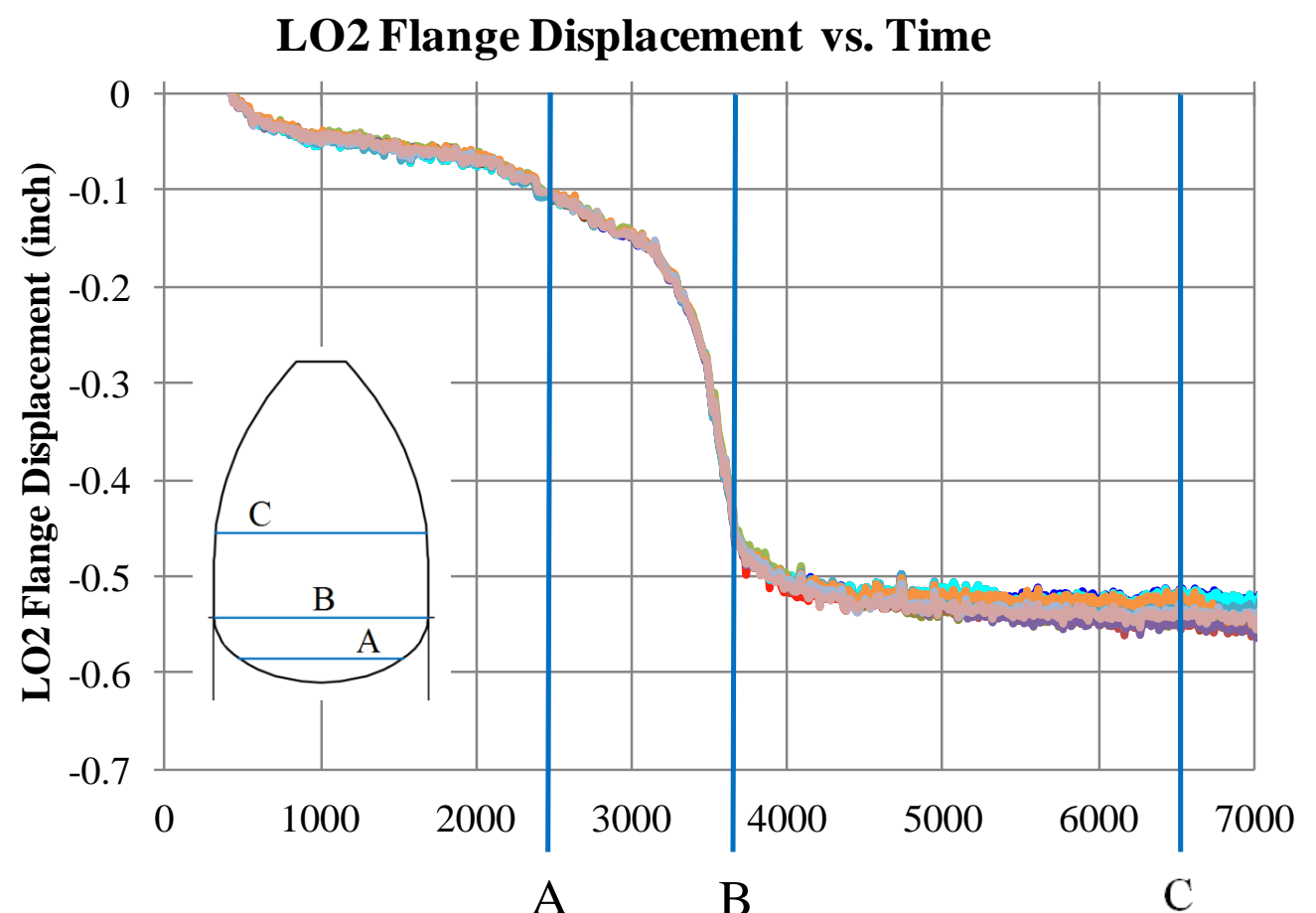

Time (seconds)

Figure 13. Flange radial displacement result (14 of 16 lines).

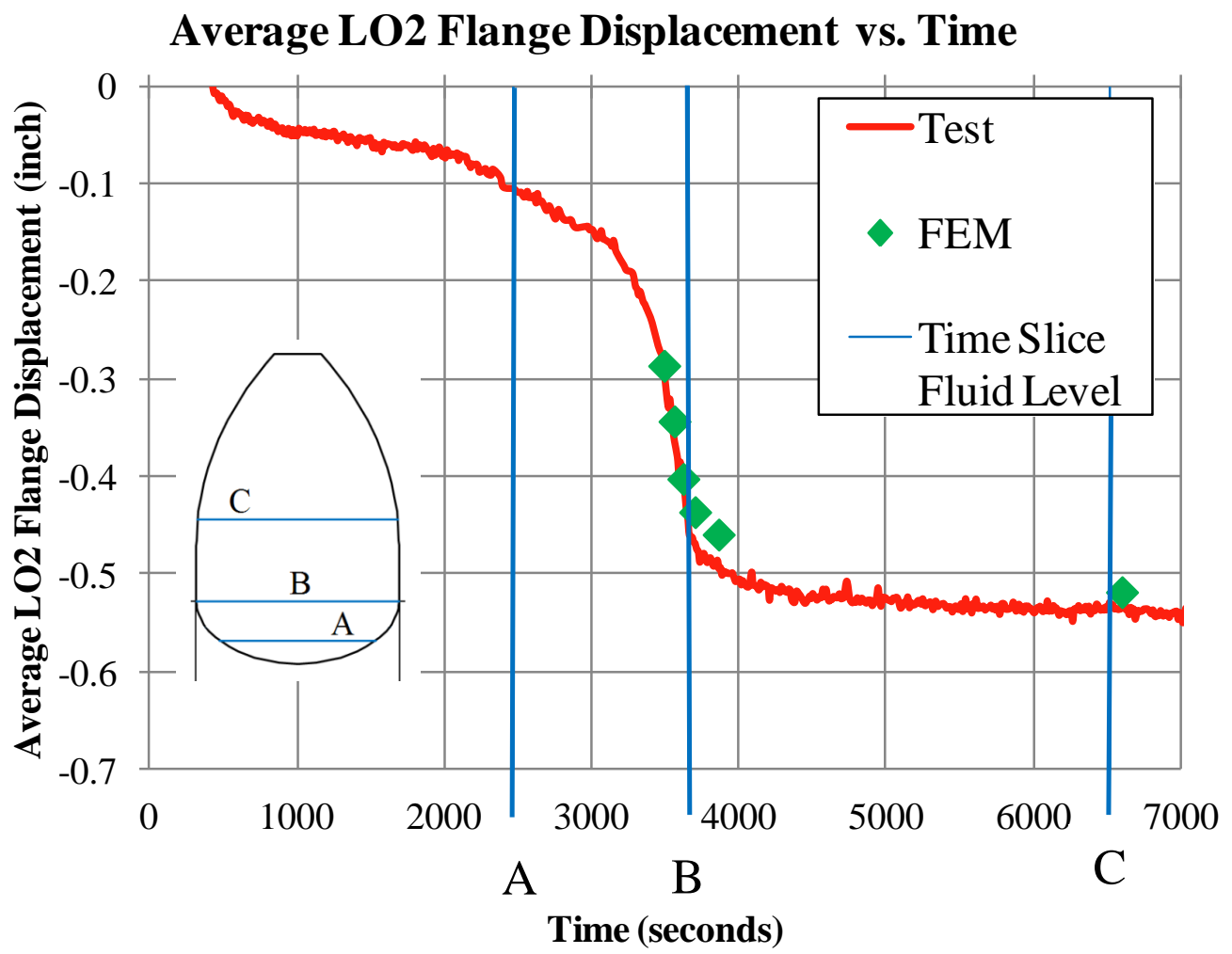

Figure 14. Average flange radial displacement compared to FEM results. 